\title{
Effects of Drugs of Abuse on Putative Rostromedial Tegmental Neurons, Inhibitory Afferents to Midbrain Dopamine Cells
}

\author{
Salvatore Lecca', Miriam Melis', Antonio Luchicchi', Maria Grazia Ennas², Maria Paola Castelli ${ }^{1,3}$, \\ Anna Lisa Muntoni, ${ }^{3,4}$ and Marco Pistis*, ${ }^{*, 3}$ \\ 'B.B. Brodie Department of Neuroscience, University of Cagliari, Monserrato, Italy; ${ }^{2}$ Department of Cytomorphology, University of Cagliari, \\ Monserrato, Italy; ${ }^{3}$ Center of Excellence for the Neurobiology of Addiction, University of Cagliari, Monserrato, Italy; ${ }^{4}$ C.N.R. Neuroscience \\ Institute-Cagliari, University of Cagliari, Monserrato, Italy
}

\begin{abstract}
Recent findings have underlined the rostromedial tegmental nucleus (RMTg), a structure located caudally to the ventral tegmental area, as an important site involved in the mechanisms of aversion. RMTg contains $\gamma$-aminobutyric acid neurons responding to noxious stimuli, densely innervated by the lateral habenula and providing a major inhibitory projection to reward-encoding midbrain dopamine (DA) neurons. One of the key features of drug addiction is the perseverance of drug seeking in spite of negative and unpleasant consequences, likely mediated by response suppression within neural pathways mediating aversion. To investigate whether the RMTg has a function in the mechanisms of addicting drugs, we studied acute effects of morphine, cocaine, the cannabinoid agonist WIN552 I2-2 (WIN), and nicotine on putative RMTg neurons. We utilized single unit extracellular recordings in anesthetized rats and whole-cell patch-clamp recordings in brain slices to identify and characterize putative RMTg neurons and their responses to drugs of abuse. Morphine and WIN inhibited both firing rate in vivo and excitatory postsynaptic currents (EPSCs) evoked by stimulation of rostral afferents in vitro, whereas cocaine inhibited discharge activity without affecting EPSC amplitude. Conversely, nicotine robustly excited putative RMTg neurons and enhanced EPSCs, an effect mediated by $\alpha 7$-containing nicotinic acetylcholine receptors. Our results suggest that activity of RMTg neurons is profoundly influenced by drugs of abuse and, as important inhibitory afferents to midbrain DA neurons, they might take place in the complex interplay between the neural circuits mediating aversion and reward.
\end{abstract}

Neuropsychopharmacology (20II) 36, 589-602; do:I 0.1038/npp.2010.190; published online 3 November 2010

Keywords: lateral habenula; aversion; addiction; patch clamp; electrophysiology; Fos

\section{INTRODUCTION}

Recent studies have provided information on how brain regions encoding aversion and reward are integrated. Mesolimbic dopamine (DA) neurons encode rewarding and appetitive stimuli with phasic excitation, whereas reward omission induces phasic inhibition (Schultz, 2007a, b). Aversive stimuli have been reported to induce both excitation (Brischoux et al, 2009) and inhibition (Ungless et al, 2004) of DA neurons, a heterogeneous response correlated to specific subgroups of DA neurons (ventral and dorsal, respectively) within the ventral tegmental area (VTA). On the other hand, glutamatergic neurons in the lateral habenula (LHb), an epithalamic region involved in the mechanisms of fear, anxiety, and stress, respond in a reverse manner, being inhibited by

*Correspondence: DR M Pistis, B.B. Brodie Department of Neuroscience, Center of Excellence for the Neurobiology of Addiction, University of Cagliari, Cittadella Universitaria, Monserrato (CA) 09042, Italy, Tel: + 39070675 4324, Fax: + 39070675 4320, E-mail: mpistis@unica.it

Received 27 May 2010; revised 10 September 2010; accepted 22 September 2010 rewards and excited by aversive stimuli (Hikosaka et al, 2008; Matsumoto and Hikosaka, 2007). Noteworthy, activity of DA and LHb neurons appears to be causally correlated, as electrical stimulation of the LHb inhibits DA neurons (Christoph et al, 1986; Ji and Shepard, 2007; Matsumoto and Hikosaka, 2007). However, the sparse innervation of DA neurons by excitatory LHb afferents (Brinschwitz et al, 2010; Omelchenko et al, 2009) unlikely explains this inhibition, and the presence of an area intermediate between the LHb and the VTA was originally postulated. Elegant studies by Jhou et al $(2009 \mathrm{a}, \mathrm{b})$ revealed that $\gamma$-aminobutyric acid (GABA) neurons in the rostromedial tegmental nucleus (RMTg), a region also denominated as 'tail' of the VTA (Perrotti et al, 2005), integrate input from the $\mathrm{LHb}$ and send output projection to midbrain DA neurons. As described, the missing link between LHb and midbrain DA neurons is provided. Notably, both RMTg and LHb neurons are phasically activated by aversive stimuli and inhibited by appetitive stimuli (Jhou et al, 2009a). In turn, RMTg neurons form inhibitory synapses with DA neurons in the VTA and the substantia nigra (Balcita-Pedicino et al, 2009), and are now accounted among the major inhibitory afferents to mesencephalic DA 
neurons (Jhou et al, 2009a). The electrical activity of DA neurons, and the resulting DA output in terminal areas, crucially depends on the balance between excitatory and inhibitory inputs (Marinelli et al, 2006). Thus, the characterization of this novel inhibitory pathway to DA neurons is of interest to understand how DA neurons respond to behavioral and pharmacological stimuli.

Understanding the relationships between brain areas encoding reward and aversion, such as the VTA and the RMTg, is also relevant when it concerns the effects of addicting drugs. As drug abuse potential can be envisaged as a balance between rewarding and aversive effects (Hutchison and Riley, 2008; Simpson and Riley, 2005; Wise et al, 1976), it can be hypothesized that the components of the appetitive properties of addicting drugs might result from both direct activation of neural reward pathways and suppression of responses in neural circuits mediating aversion. Indeed, one of the hallmarks of drug addiction is the perseverance of drug taking despite of negative and unpleasant consequences of drug use. Recent studies indicate that drugs of abuse affect GABA neurons in the RMTg: these neurons, and notably those projecting to the VTA, express $\Delta$ FosB (Kaufling et al, 2009; Perrotti et al, 2005) and c-Fos following repeated cocaine exposure (Geisler et al, 2008). In addition, RMTg neurons are immunoreactive against $\mu$-opioid receptors (Jhou et al, $2009 \mathrm{~b})$ and supposedly respond to opioid administration (Jhou et al, 2009c).

To determine further whether RMTg neurons are a primary target of drugs of abuse, we took advantage of extracellular single unit recordings in anesthetized rats together with whole-cell patch-clamp recordings in brain slices. We characterized the electrophysiological features of putative neurons in the RMTg, identified by their excitatory responses to both a noxious stimulus (ie, paw pinch) and $\mathrm{LHb}$ stimulation. We also studied the effects of the prototypical psychostimulant and opioid (cocaine and morphine, respectively), the type 1-cannabinoid (CB1) receptor agonist WIN55212-2 (WIN), and nicotine on firing rate in vivo and on excitatory postsynaptic currents (EPSCs) in vitro.

\section{MATERIALS AND METHODS}

\section{In Vivo Electrophysiology}

Male Sprague-Dawley albino rats (Harlan Nossan, San Pietro al Natisone, Italy) weighing 250-350 $\mathrm{g}$ were used in all in vivo experiments. Experiments were performed in strict accordance with EEC Council Directive of 24 November 1986 (86/609).

All efforts were made to minimize pain and suffering and to reduce the number of animals used.

Animals were housed in groups of three to six in standard conditions of temperature and humidity under a 12-h light/ dark cycle (with lights on at 0700 hours) with food and water available ad libitum. We anesthetized rats with urethane $(1300 \mathrm{mg} / \mathrm{kg}$, intraperitoneally (i.p.)), cannulated their femoral vein for intravenous (i.v.) administration of pharmacological agents, and placed them in the stereotaxic apparatus (Kopf, Tujunga, CA) with their body temperature maintained at $37 \pm 1^{\circ} \mathrm{C}$ by a heating pad.
Experiments in the RMTg. The skull surface was exposed and a burr hole was drilled over the RMTg (7.0-7.4 mm posterior to bregma, $0.8-1.0 \mathrm{~mm}$ lateral to the midline, 6.5-7.5 mm ventral to the cerebellar cortex) for the insertion of a recording electrode. For orthodromic stimulation experiments, a Formvar-coated stainless steel bipolar electrode $(250 \mu \mathrm{m}$ tip diameter $)$ was inserted in the ipsilateral $\mathrm{LHb}(1.9 \mathrm{~mm}$ posterior to bregma, $0.7 \mathrm{~mm}$ lateral to the midline, $4.7 \mathrm{~mm}$ ventral to the cerebral cortex) with an inclination of $20^{\circ}$ anteroposterior on the coronal plane.

Structures were localized according to the stereotaxic atlas of Paxinos and Watson (2007). Single unit activity of RMTg cells was recorded extracellularly by glass micropipettes filled with $2 \%$ Pontamine sky blue dye dissolved in $0.5 \mathrm{M}$ sodium acetate (impedance 5-10 M $\Omega$ ). Putative GABA-containing neurons in the RMTg were first isolated and identified according to previously described electrophysiological characteristics (Jhou et al, 2009a), including a relatively high spontaneous firing rate $(>10 \mathrm{~Hz})$ and a biphasic and short ( $<1.5 \mathrm{~ms}$, see Results for more details) action potential. Once a cell was selected, stimuli $(\sim 0.5 \mathrm{~mA})$ were delivered to the $\mathrm{LHb}$ at $1 \mathrm{~Hz}$. Responses to electrical stimulation of the $\mathrm{LHb}$ were evaluated and a peri-stimulus time histogram (PSTH) was generated on-line (Spike 2 software, CED, Cambridge, UK) for each neuron. Only RMTg neurons with a robust excitatory response (latency range $2-8 \mathrm{~ms}$ ) to $\mathrm{LHb}$ stimulation were selected in this study. We did not include cells whose onset latencies were longer than $8 \mathrm{~ms}$ following LHb stimulation because they could exhibit a polysynaptic response component.

The extracellular neuronal signal was filtered (bandpass $1-3 \mathrm{kHz}$ ) and amplified (Neurolog System, Digitimer, Hertfordshire, UK), displayed on a digital storage oscilloscope (TDS 3012, Tektronix, Marlow, UK) and digitally recorded. Experiments were sampled on- and off-line by a computer connected to CED Power 1401 laboratory interface (Cambridge Electronic Design, Cambridge, UK). The spontaneous firing rate was recorded for $2-3 \mathrm{~min}$ to establish a baseline measure of firing rate. Interspike intervals and coefficient of variation $(C V=S D$ of interspike intervals divided by the mean interspike interval; a measure of firing regularity) were also determined.

Drugs were administered in bolus i.v. ( $1 \mathrm{ml} / \mathrm{kg}$ of body weight). Changes in firing rate and regularity were calculated by averaging the effects of the drugs for the 2-min period following drug administration and comparing them to the mean of the pre-drug baseline. When drugs were administered, only one cell was recorded per rat.

At the end of recording sessions, DC current $(15 \mathrm{~mA}$ for $5 \mathrm{~min}$ ) was passed through the recording micropipette in order to eject Pontamine sky blue for marking the recording site. Brains were then rapidly removed and fixed in $4 \%$ paraformaldehyde solution. The position of the electrodes was microscopically identified on serial sections $(60 \mu \mathrm{m})$ stained with Neutral Red.

Experiments in the VTA. The scalp was retracted and one burr hole was drilled above the VTA $(6.0 \mathrm{~mm}$ posterior from bregma, $0.3-0.6 \mathrm{~mm}$ lateral from midline) for the placement of a recording electrode. To evaluate the inhibitory input arising from the RMTg to the VTA, a Formvar-coatedstimulating stainless steel bipolar electrode $(250 \mu \mathrm{m}$ tip 
diameter) was inserted in the ipsilateral RMTg $(9.6 \mathrm{~mm}$ posterior from bregma, $0.8 \mathrm{~mm}$ lateral from the midline, $7.0 \mathrm{~mm}$ ventral from the cortical surface) with an inclination of $20^{\circ}$ anteroposterior on the coronal plane. Single unit activity of neurons located in the VTA (V 7.0-8.0 mm from the cortical surface) was recorded extracellularly with the same instruments previously described for the RMTg experiments. Single units were isolated and identified according to already published criteria (Grace and Bunney, 1983, 1984; Ungless et al, 2004). We recorded VTA DA neurons when all criteria for identification were fulfilled: firing rate $\leqslant 10 \mathrm{~Hz}$, duration of action potential $\geqslant 2.5 \mathrm{~ms}$, inhibitory responses to hindpaw pinching. Once a cell was selected, stimuli $(\sim 0.5 \mathrm{~mA})$ were delivered to the RMTg at $1 \mathrm{~s}$ intervals and stimulation currents were progressively adjusted to induce an inhibitory response after each stimulus. The experimental protocol was essentially that published by Ji and Shepard (2007). Responses to electrical stimulation of RMTg were evaluated and a PSTH was generated on-line (Spike 2) for each neuron. Histological verification was carried out as described above.

\section{In Vitro Electrophysiology}

Experiments in the RMTg. Whole-cell patch-clamp recordings from Sprague-Dawley rat cells were as described previously (Melis et al, 2008). Briefly, male rats (14-31 days) were anesthetized with halothane and killed. A block of tissue containing the midbrain was rapidly dissected and sliced in the horizontal plane $(300 \mu \mathrm{m})$ with a vibratome (VT1000S, Leica) in ice-cold low- $\mathrm{Ca}^{2+}$ solution containing (in $\mathrm{mM}$ ) $126 \mathrm{NaCl}, 1.6 \mathrm{KCl}, 1.2 \mathrm{NaH}_{2} \mathrm{PO}_{4}, 1.2 \mathrm{MgCl}_{2}, 0.625$ $\mathrm{CaCl}_{2}, 18 \mathrm{NaHCO}_{3}$, and 11 glucose. Slices were transferred to a holding chamber with artificial cerebrospinal fluid (ACSF, $37^{\circ} \mathrm{C}$ ) saturated with $95 \% \mathrm{O}_{2}$ and $5 \% \mathrm{CO}_{2}$ containing (in mM) $126 \mathrm{NaCl}, 1.6 \mathrm{KCl}, 1.2 \mathrm{NaH}_{2} \mathrm{PO}_{4}, 1.2 \mathrm{MgCl}_{2}, 2.4$ $\mathrm{CaCl}_{2}, 18 \mathrm{NaHCO}_{3}$, and 11 glucose. Slices (two per animal) were allowed to recover for at least $1 \mathrm{~h}$ before being placed (as hemislices) in the recording chamber and superfused with the ACSF $\left(37^{\circ} \mathrm{C}\right)$ saturated with $95 \% \mathrm{O}_{2}$ and $5 \% \mathrm{CO}_{2}$. Putative RMTg cells were visualized with an upright microscope with infrared illumination (Axioskop FS 2 plus, Zeiss), and whole-cell current- and voltage-clamp recordings (one per hemislice) were made by using an Axopatch 200B amplifier (Molecular Devices, CA). Current-clamp experiments were made with electrodes filled with a solution containing the following (in $\mathrm{mM}$ ): $144 \mathrm{KCl}, 10$ HEPES, 3.45 BAPTA, $1 \mathrm{CaCl}_{2}, 2.5 \mathrm{Mg}_{2} \mathrm{ATP}$, and 0.25 $\mathrm{Mg}_{2} \mathrm{GTP}$ ( $\mathrm{pH} 7.2-7.4,275-285$ mOsm). All voltage-clamp recordings were made with electrodes filled with a solution containing the following (in $\mathrm{mM}$ ): $117 \mathrm{Cs}$ methansulfonic acid, 20 HEPES, 0.4 EGTA, $2.8 \mathrm{NaCl}, 5 \mathrm{TEA}-\mathrm{Cl}, 2.5 \mathrm{Mg}_{2} \mathrm{ATP}$, and $0.25 \mathrm{Mg}_{2} \mathrm{GTP}$ ( $\mathrm{pH}$ 7.2-7.4, 275-285 mOsm). Experiments were begun only after series resistance had stabilized (typically 15-40 M $\Omega$ ). Series and input resistance were monitored continuously on-line with a $5 \mathrm{mV}$ depolarizing step $(25 \mathrm{~ms})$. Estimated resting potential was calculated by averaging $\mathrm{Vm}$ values measured $1 \mathrm{~ms}$ before the initiation of each spontaneous action potential. Data were filtered at $2 \mathrm{kHz}$, digitized at $10 \mathrm{kHz}$, and collected on-line with acquisition software (pClamp 8.2, Molecular Devices). A bipolar stainless steel-stimulating electrode (FHC) was placed $150 \mu \mathrm{m}$ rostral to the recording electrode to stimulate (duration $50 \mu \mathrm{s}$ ) the afferent fibers at a frequency of $0.1 \mathrm{~Hz}$. Paired stimuli were given with an interstimulus interval of $50 \mathrm{~ms}$, and the ratio between the second and the first EPSC was calculated and averaged for a $5 \mathrm{~min}$ baseline. Each slice received only a single drug exposure.

\section{Stimulation of RMTg FOS Expression and Immunofluorescent Staining}

In a separate set of experiments, animals were first prepared for in vivo recordings as described above. The i.p. injection of $(+)$ methamphetamine hydrochloride $(10 \mathrm{mg} / \mathrm{kg}$ in $0.9 \%$ saline; $1 \mathrm{ml} / \mathrm{kg}$ ) given $2 \mathrm{~h}$ prior killing was used to produce Fos expression in the RMTg, as previously described by Jhou et al (2009b). See Supplementary Materials and Methods for detailed information.

\section{Drugs}

Morphine and cocaine hydrochloride were purchased from S.a.l.a.r.s (Como, Italy) and Akzo Pharmadivision Diosynth (Oss, Netherlands), respectively. Nicotine ((-)-nicotine hydrogen tartrate), mecamylamine, and $(+)$ methamphetamine hydrochloride were purchased from Sigma (Milano, Italy). WIN, methyllycaconitine, and AM281 were purchased from Tocris (Bristol, UK). Naloxone was purchased from RBI (Natick, MA). SR141716A was a generous gift of Sanofi-Aventis Recherche (Montpellier, France). For experiments in vivo, WIN and SR141716A were emulsified in $1 \%$ Tween 80 , then diluted in saline, and sonicated. All other drugs were diluted in saline. Nicotine solution was adjusted to $\mathrm{pH}=7.0$ with $\mathrm{NaOH}$. For experiments in vitro, all drugs were applied in known concentrations to the superfusion medium and, with the exception of WIN and AM281, were dissolved in saline. WIN and AM281 were dissolved in DMSO as stock concentrations and the final concentration of DMSO was $<0.01 \%$.

\section{Statistical Analysis}

Drug-induced changes in rate and regularity of action potential activity were calculated by averaging the effects after drug administration ( $2 \mathrm{~min}$ ) and normalizing to the pre-drug baseline. All the numerical data are given as mean \pm SEM. Data were compared and analyzed by using two-way ANOVA for repeated measures (treatment $\times$ time), or one-way ANOVA or Student's $t$-test for repeated measures, when appropriate. Post hoc multiple comparisons were made using the Dunnett's or Bonferroni's tests. Statistical analysis was performed by means of the Graphpad Prism software (La Jolla, CA). The significance level was established at $p<0.05$.

\section{RESULTS}

\section{Electrophysiological Characterization of RMTg Neurons}

We recorded the spontaneous activity of single putative RMTg neurons ( $n=41$, from nine rats) in urethane-anesthetized rats. Relatively high spontaneous firing rate $(>10 \mathrm{~Hz})$ and short $(<1.5 \mathrm{~ms})$, biphasic action potential of RMTg cells recorded extracellularly were consistent with those recently 
described in behaving rats (Jhou et al, 2009a). The action potential waveform of RMTg neurons $(n=41)$, filtered using standard bandpass settings of $1-3 \mathrm{kHz}$, was characterized by an initial negative phase followed by a positive one (see Figure 1a). The mean duration from the start to the positive trough was $1.26 \pm 0.04 \mathrm{~ms}$ (range $0.90-1.49 \mathrm{~ms}$, $n=41$ ). The width of the neuronal action potentials was longer in our study when compared with that of Jhou et al (2009a) because of the difference in the experimental conditions (anesthetized $v s$ behaving rats, filtering parameters). In general, RMTg neurons fired regularly at an average basal rate of $15.5 \pm 1.0 \mathrm{~Hz}(n=41)$ (Figure 1a). The regularity of firing was quantified by the $\mathrm{CV}$ of interspike intervals (mean $\mathrm{CV}=36.8 \pm 3.3 \%, n=41$ ) (see Material and Methods for CV detail). A typical interspike interval histogram showing the relatively constant interspike intervals, and their unimodal distribution peaking at around $50 \mathrm{~ms}$, is shown in Figure 1a.

All in vitro data presented were obtained from cells $(n=57)$ located within the RMTg, identified in the horizontal slice as the region posterior $(\sim 1 \mathrm{~mm})$ to the VTA (Figure 1b), which is in turn placed medially to the medial terminal nucleus of the accessory optic tract (MT) and laterally to the interpeduncular fossa (Paxinos and Watson, 2007). Under current-clamp mode in a whole-cell configuration, all of the neurons recorded $(n=22)$ were spontaneously active with a mean firing rate of $4.7 \pm 0.3 \mathrm{~Hz}$ within a range of $3-9 \mathrm{~Hz}$ (Figure 1c). The estimated resting membrane potential was $-44.5 \pm 9.9 \mathrm{mV}$, and putative RMTg cells fired short-duration spikes (mean width at threshold: $1.77 \pm 0.01 \mathrm{~ms}$ ), whose amplitude and input resistance were $65.0 \pm 0.8 \mathrm{mV}$ and $304 \pm 37 \mathrm{M} \Omega$, respectively. These electrophysiological features are similar to those described for GABA neurons of the neighbor pars reticulata of the substantia nigra recorded under the same conditions (Atherton and Bevan, 2005). EPSCs were evoked by repetitively stimulating the afferents (duration $50 \mu \mathrm{s}$, frequency $0.1 \mathrm{~Hz}$, intensity $0.01-0.30 \mathrm{~mA}$ ) with a stimulating electrode that was placed rostro-laterally $(\sim 150 \mu \mathrm{m})$ from the recording electrode (Figure $1 \mathrm{~b}$ ), and pharmacologically isolated by continuous perfusion of the $\mathrm{GABA}_{\mathrm{A}}$ antagonist picrotoxin $(100 \mu \mathrm{M})$. Bath application of $10 \mu \mathrm{m}$ 6-cyano-7-nitroquinoxaline-2,3-dione completely suppressed these currents (Figure 1c), indicating that they are AMPA-mediated EPSCs. EPSCs had a half-rise time of $1.36 \pm 0.20 \mathrm{~ms}(n=35)$ and a decay time constant of

a
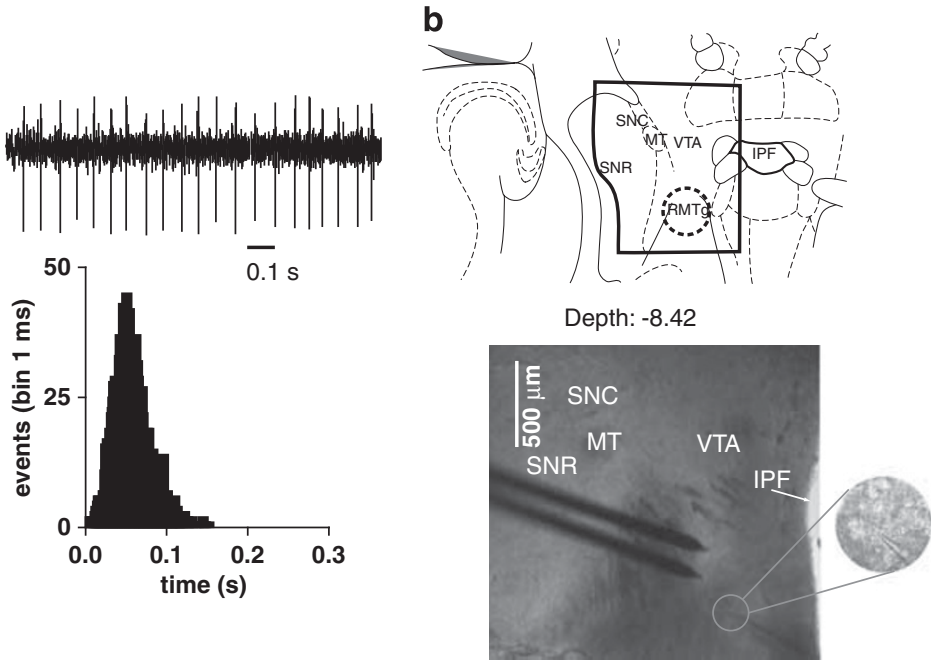
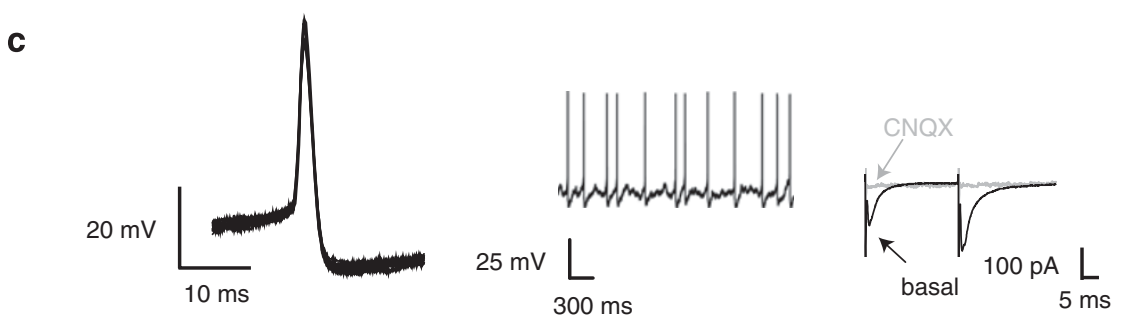

Figure I Characterization of neurons in the rostromedial tegmental nucleus (RMTg). (a) Traces illustrating representative extracellular recordings of a putative GABA neuron in the RMTg of an anesthetized rat. The left trace shows typical superimposed spike waveforms characterized by an initial negative deflection followed by a positive phase. The right trace shows the typical fast firing rate and regular pattern of an RMTg neuron. The representative interspike interval histogram shows the regularity of discharge pattern. (b) Identification of RMTg in the horizontal section in the brain slice preparation. The RMTg was identified as the region posterior to the ventral tegmental area (VTA), which is located medially to the medial terminal nucleus of the accessory optic tract (MT) and laterally to the interpeduncular fossa (IPF). The stimulating electrode is placed rostro-laterally to the recording electrode (at a distance of $\sim 150 \mu \mathrm{m}$ ), whose position is posterior to the VTA (at a distance of $\sim 1 \mathrm{~mm}$ ). A recorded putative RMTg neuron is visualized in the inset. SNC, substantia nigra pars compacta, SNR, substantia nigra pars reticulata. The number indicates the ventral coordinate with reference to the horizontal plane passing through the skull surface at bregma, as in Paxinos and Watson (2007). (c) The electrophysiological properties exhibited by the neuron in (b) were similar to all of the neurons recorded in the study. RMTg cell physiology includes short-duration spikes (left panel, superimposed traces), regular spontaneous activity at rest (middle panel). The right panel displays typical whole-cell patch-clamp recordings and shows that bath application of $10 \mu \mathrm{M} 6$-cyano-7-nitroquinoxaline2,3-dione (CNQX) completely suppressed evoked postsynaptic currents (EPSCs) when cells are held at $-70 \mathrm{mV}$, indicating that they are AMPA mediated. Traces show paired EPSCs from a typical experiment, before (basal, black line) and during superfusion of CNQX (gray line). 
$4.71 \pm 0.06 \mathrm{~ms}(n=35)$. Although we cannot identify definitively the sources of excitatory afferents in this slice preparation, we can assume that most of the rostral inputs electrically stimulated in our preparation are presumably originating from the $\mathrm{LHb}$, given that it is one of the major excitatory sources to the RMTg passing through the VTA (Jhou et al, 2009a).

Jhou et al (2009a) recently showed that aversive stimuli induce Fos expression in VTA-projecting RMTg neurons, and phasically stimulate their electrical activity in behaving rats. Notably, a substantial number of VTA-projecting RMTg cells receive a major afferent from the LHb (Jhou et al, 2009b), thus corroborating the idea that RMTg might signal aversive events and inhibit midbrain DA neurons. Hence, in vivo we first tested the responses of putative RMTg neurons to a standard aversive somatosensory stimulus (hindpaw mechanical stimulation), which is known to exceed the threshold of pain in freely moving animals (Cahusac et al, 1990).

Following 2-3 min of stable baseline firing rate, a brief ( $\sim 2-4 \mathrm{~s})$ pinch was applied to the hindpaw ipsilateral to the recording site and the response analyzed during the $5 \mathrm{~s}$ after stimulus onset (Figure $2 \mathrm{a}$ ). In agreement with recent data (Jhou et al, 2009a), we found that a majority $(73.2 \%, 30$ out of 41) of putative RMTg neurons were significantly stimulated by paw pinch. The overall response of RMTg neuronal population to the pinch stimulus is illustrated in Figure 2a: phasic excitation peaked at around $2 \mathrm{~s}$ after the onset of the paw pinch $(237.3 \pm 40.9 \%$ of baseline firing rate; $n=12 ; \quad \mathrm{F}_{13,43}=6.7 ; \quad p<0.0001 ; \quad$ one-way ANOVA and Dunnett's test).

We next examined the response of putative RMTg neurons to electrical stimulation of the LHb. Single-pulse stimulation $(0.5 \mathrm{~mA}, 0.5 \mathrm{~ms}, 1 \mathrm{~Hz})$ of the LHb enhanced spiking activity in $46.3 \%$ (19/41) of RMTg neurons sampled with a mean onset latency of $5.5 \pm 0.3 \mathrm{~ms}$ after current ejection (Figure $2 \mathrm{~b}$ ). The majority (15 out of 19) of RMTg neurons responding to LHb stimulation were also 'pinch excited.' The remaining (22 out of 41) cells tested failed to respond to LHb stimulation.

Notably, Ji and Shepard (2007) reported that LHb stimulation transiently suppressed the activity of $97 \%$ of midbrain DA neurons through a $\mathrm{GABA}_{\mathrm{A}}$ receptor-mediated mechanism. This inhibition unlikely is monosynaptic, being relayed by GABA neurons in the $\mathrm{RMTg}$, which receive a major LHb input, and heavily project to midbrain DA neurons (see Jhou et al, 2009b). To investigate this possibility, in a separate series of experiments, the effect of RMTg stimulation on the spontaneous firing rate of DA neurons in the VTA was examined. As expected, singlepulse electrical stimulation $(0.5 \mathrm{~mA}, 0.5 \mathrm{~ms}, 1 \mathrm{~Hz})$ of the RMTg resulted in a short term, though complete, suppression of VTA DA neuron activity (Figure 2c). Peri-stimulus histograms and CUMSUM plots showing the typical responses of these cells to a $0.5 \mathrm{~mA}$ current pulse are illustrated in Figure 2c. The duration of inhibition averaged $124.8 \pm 13.2 \mathrm{~ms}(n=10)$ (see Figure $2 \mathrm{c}$ ). The stimulating and recording sites were verified to be within the RMTg and the VTA, respectively (Paxinos and Watson, 2007). a
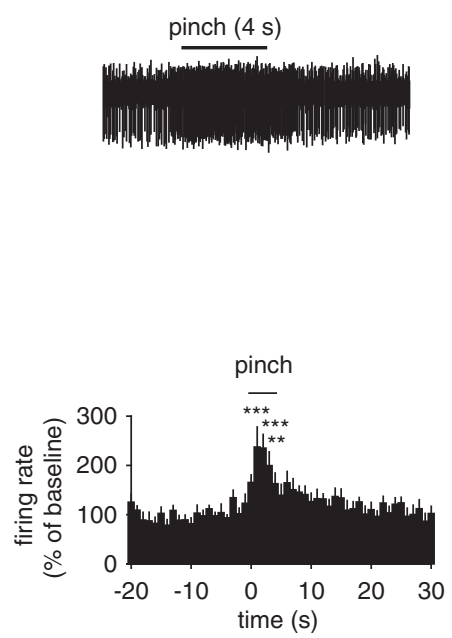

b
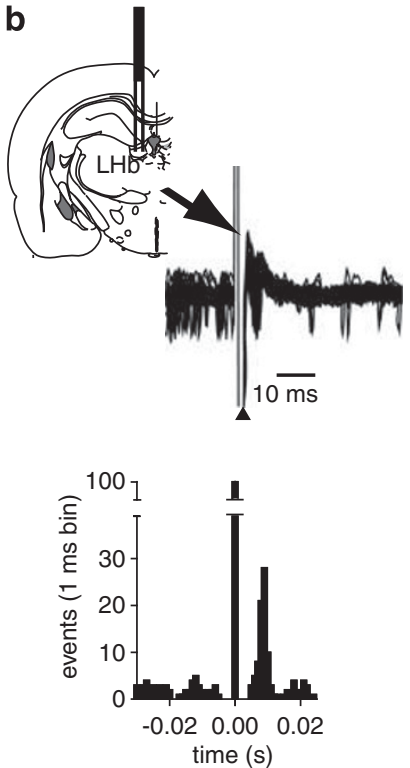

C
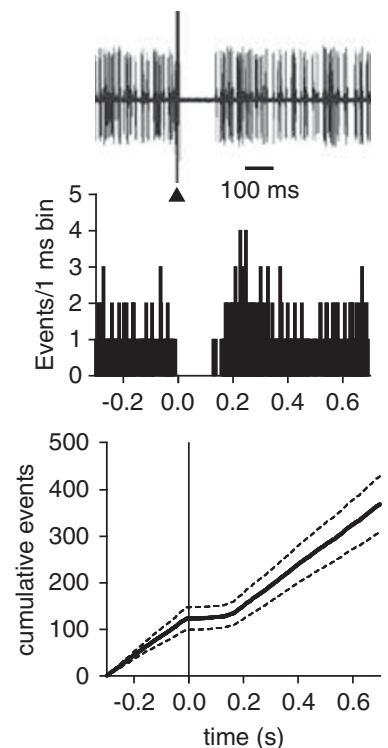

Figure 2 Neurons in the rostromedial tegmental nucleus (RMTg) exhibit a fast and phasic increase in firing rate after paw pinch, are excited by lateral habenula, and inhibit dopamine (DA) neurons. (a) Typical recording from a putative RMTg neuron showing the rapid and phasic increase in firing activity during paw pinch. The average rate histogram (I s bin) is shown $(n=12)\left(* * * p<0.00\right.$ I, ${ }^{*} *<<0.0$ I; one-way ANOVA and Dunnett's test). (b) Superimposed traces acquired from a digital storage oscilloscope showing a relatively constant latency of the orthodromic responses of RMTg neuron after LHb stimulation (top). The arrowhead indicates the artifacts produced by LHb stimulation. The coronal plate indicates the position of the stimulating electrode. Representative peri-stimulus time-histogram displaying the typical response of a recorded putative RMTg neuron during LHb stimulation (bottom). (c) Traces acquired from a digital oscilloscope (top) and peri-stimulus time histogram of the same cell (middle), comprising 100 consecutive sweeps, showing that RMTg stimulation induces a complete inhibition of discharge activity of a VTA DA neuron (top) for $\sim 100$ ms. Stimuli consisted of rectangular current pulses $(0.5 \mathrm{~mA}, 0.5 \mathrm{~ms})$ delivered I $\mathrm{s}$ after the start of each sweep (middle). Graph showing the average CUMSUM plots of I0 VTA DA neurons under RMTg stimulation (bottom). The graph was generated by adding the contents of consecutive bins in the corresponding peri-stimulus time histograms to create a cumulative total average and SEM of the number of spikes recorded across trials. 


\section{Methamphetamine-Induced Fos Expression Within RMTg Recording Sites}

The RMTg is a newly characterized brain region and poorly defined anatomically. Although we selected for our experiments only cells fulfilling precise electrophysiological criteria, the correct localization of recording sites is crucial. Figure 3 shows that these sites were localized within the RMTg region as recently defined (Jhou et al, 2009a, b; Kaufling et al, 2009) (Figure 3a and b). In addition, the RMTg is reliably identified by accumulation of Fosimmunoreactive (Fos-IR) neurons following pharmacological stimuli, such as an acute methamphetamine administration (Jhou et al, 2009b). To verify that the recording sites (marked with Pontamine sky blue) were located in the RMTg, we carried out electrophysiological experiments as described above and thereafter induced Fos expression by injecting methamphetamine $(10 \mathrm{mg} / \mathrm{kg}$, i.p., $2 \mathrm{~h}$ before killing). We used a specific antibody for c-Fos raised against a synthetic peptide corresponding to amino acids 4-17 of human c-Fos, which reacts with rat Fos proteins but not with Jun protein. As previously described (Jhou et al, 2009b; Kaufling et al, 2009), $2 \mathrm{~h}$ after methamphetamine administration, Fos-IR cells were found in the RMTg, which resides within and ventral to the superior cerebellar decussation (xscp) (Figure 3). As shown in Figure $3 \mathrm{c}$ and $\mathrm{d}$, clusters of Fos-IR neurons are observed in the RMTg, symmetrically to the electrophysiological recording site marked with Pontamine sky blue (which appears red at wavelength $594-617 \mathrm{~nm}$ ).

\section{Effects of Drugs of Abuse on RMTg Neurons}

The firing rate of GABA neurons within the RMTg is inhibited by natural rewards like food or reward predictive stimuli, and, conversely, stimulated by aversive stimuli (Jhou et al, 2009a). However, it is not known whether exposure to drugs of abuse influence RMTg neuronal activity. Ergo, we investigated the electrophysiological effects of four major addicting drugs (ie morphine, cocaine, the cannabinoid receptor agonist WIN, and nicotine) on putative RMTg neurons both in vivo and in vitro. In vivo, all neurons were identified by their excitatory responses to both electrical stimulation of the LHb and paw pinch. Only cells whose correct localization was confirmed histologically were included in the study.

Morphine. The RMTg is immunoreactive against $\mu$-opioid receptors (Jhou et al, 2009b). Accordingly, rats selfadminister the $\mu$-opioid receptor agonist endomorphin-1 into the RMTg, but not into the regions dorsal, ventral, or lateral to it (Jhou et al, 2009c). Therefore, we first assessed if the $\mu$-opioid receptor agonist morphine modulates the neuronal activity of RMTg neurons. We selected seven neurons that responded to both LHb stimulation and paw pinch. Systemic administration of morphine $(4 \mathrm{mg} / \mathrm{kg}$, i.v.)
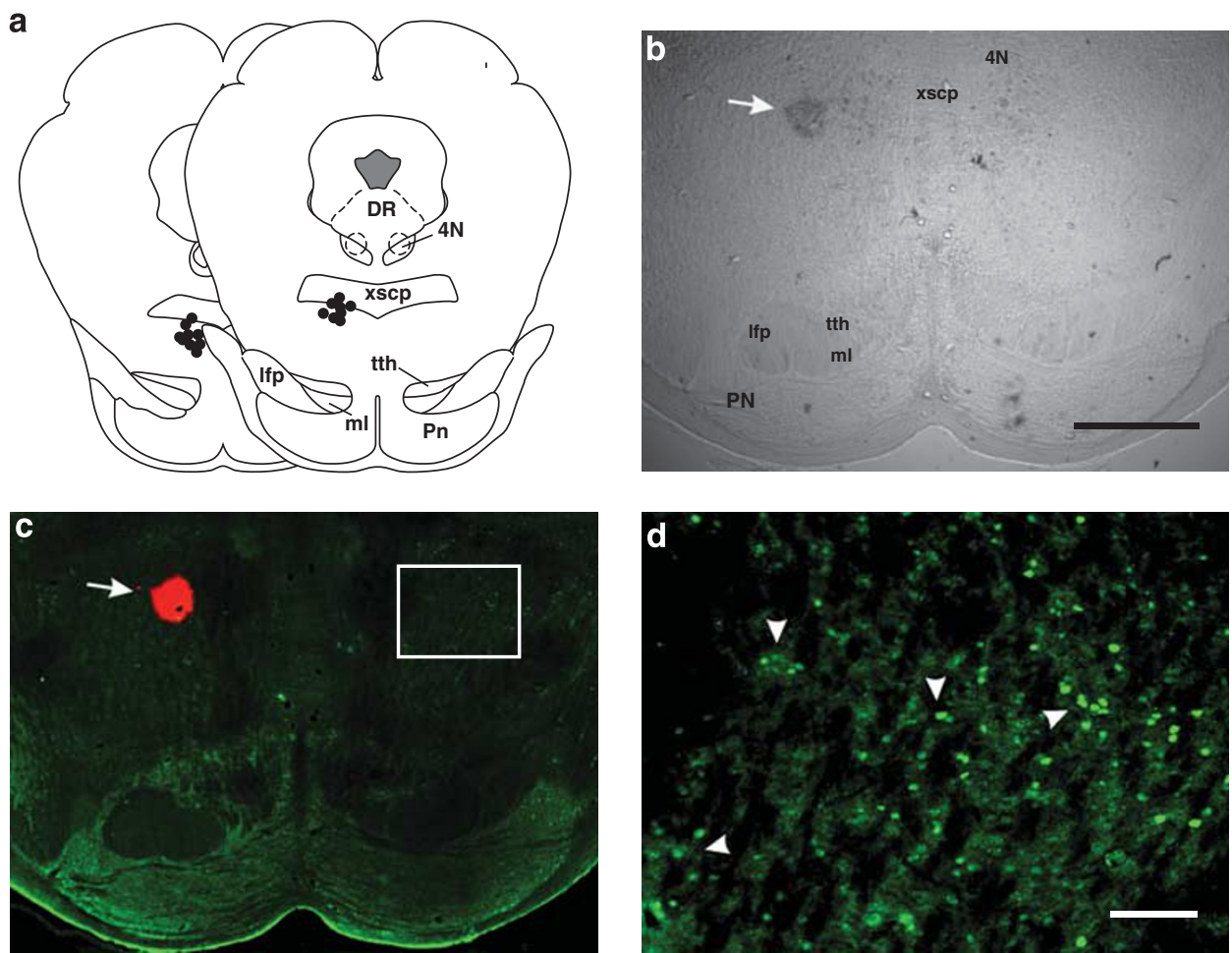

Figure 3 Methamphetamine-induced Fos immunoreactivity within the rostromedial tegmental nucleus (RMTg). The rat from which the brain sections were taken received an injection of methamphetamine ( $10 \mathrm{mg} / \mathrm{kg}$, i.p.) $2 \mathrm{~h}$ prior to killing. (a) Schematic redrawing of coronal plates (based on Paxinos and Watson, 2007) including the RMTg (bregma AP-7.2 and -7.44) showing Pontamine sky blue labeling sites (black dots). (b) Microphotograph of a transmitted light image showing the Pontamine sky blue dye (arrow). (c) This section shows Fos immunostaining (green). The arrow indicates the dye, which appears red at wavelength 594-617 nm. (d) Higher magnification of the white-boxed area in (c) revealing Fos-positive nuclei inside the RMTg (arrowheads). $4 \mathrm{~N}$, trochlear nucleus; DR, dorshal raphe nuclei; Ifp, longitudinal fasciculus of the pons; ml, medial lemniscus; Pn, pontine nuclei; th, trigeminothalamic tract; xscp, superior cerebellar peduncle decussation; scale bars, $1000 \mu \mathrm{m}$ in (b-c); $100 \mu \mathrm{m}$ in (d). 
strongly inhibited the spontaneous firing rate of putative RMTg neurons $\left(49.7 \pm 8.6 \%\right.$ of baseline; $n=7 ; \mathrm{F}_{5,30}=13.02$, $p<0.0001$; one-way ANOVA and Dunnett's test) (Figure 4a and c). This effect required the activation of $\mu$-opioid receptors, as pretreatment with the $\mu$-opioid receptor antagonist naloxone $(0.1 \mathrm{mg} / \mathrm{kg}$, i.v., $4 \mathrm{~min}$ before morphine) fully prevented morphine-induced suppression of RMTg neuron activity $\left(103.5 \pm 7.2 \%\right.$ of baseline level; $n=4 ; \mathrm{F}_{1,45}=14.55$; $p<0.01$ vs morphine; two-way ANOVA and Bonferroni's test) (Figure $4 \mathrm{~b}$ and $\mathrm{c}$ ). Morphine did not significantly affect firing regularity (basal CV: $45.1 \pm 9.8 \%$; morphine $\mathrm{CV}$ : $46.3 \pm 7.2 \% ; p>0.05$, Student's $t$-test).

To investigate whether or not $\mu$-opioid receptor activation might affect excitatory synaptic transmission onto putative RMTg cells in vitro, we measured EPSCs recorded from these neurons while holding them in a voltage-clamp mode at $-70 \mathrm{mV}$. Bath application of morphine at a concentration of $1 \mu \mathrm{M}(3 \mathrm{~min})$ significantly reduced EPSCs (by $40.0 \pm$ $15.0 \% ; n=5 ; \mathrm{F}_{18,72}=3.417 ; p=0.0001$; one-way ANOVA for repeated measures) (Figure $4 \mathrm{~d}$ ). Morphine did not significantly affect either the mean value of the decay time constant $(5.06 \pm 0.10$ and $5.14 \pm 0.05 \mathrm{~ms}$ in the absence and presence of morphine, respectively) or the holding current $(5.56 \pm 3.01 \mathrm{pA})$. However, a decreased input resistance (from $0.42 \pm 0.05$ to $0.32 \pm 0.06 \mathrm{G} \Omega$; paired $t$-test, $p<0.05$ ) was detected, which might contribute to the reduction in EPSC amplitude. The effect of morphine was reversible on wash out, and it was fully abolished in the presence of naloxone $\left(0.1 \mu \mathrm{M} ; n=5 ; \mathrm{F}_{1,152}=23.77 ; p=0.0012\right.$; two-way ANOVA) (Figure 4e). The reduction of EPSC amplitude observed could be explained by either a presynaptic effect on glutamate release, a postsynaptic change of the AMPA receptors, or a combination of these. We, therefore, measured the paired-pulse ratio, whose modifications are considered to reflect changes in transmitter release (Melis et al, 2002; Nie et al, 2004). Morphine did not modify the paired-pulse ratio (EPSC2/EPSC1 from $0.88 \pm 0.10$ to $0.91 \pm 0.10 ; \quad n=5$, paired $t$-test $t=0.20 ; \quad p=0.849$ ) (Figure $4 \mathrm{f}$ ), suggesting that it might reduce EPSC amplitude at a postsynaptic site.

Cocaine. GABA neurons in the RMTg have been shown to display strong Fos, FosB, and $\triangle$ FosB activation after both acute and chronic exposure to psychostimulants (ColussiMas et al, 2007; Geisler et al, 2008; Jhou et al, 2009b; Kaufling et al, 2009; Perrotti et al, 2005), thus suggesting a potential role for this area in psychostimulant rewardrelated effects. Therefore, we investigated the possibility that cocaine might influence RMTg neuron discharge activity. We recorded seven cells identified by both their excitatory response to $\mathrm{LHb}$ stimulation and paw pinch. Acute injection of cocaine $(1 \mathrm{mg} / \mathrm{kg}$, i.v.) caused a transient depression of firing rate of putative RMTg neurons $\left(82.1 \pm 6.0 \%\right.$ of baseline level; $n=7 ; \mathrm{F}_{5,30}=2.58 ; p<0.05$; one-way ANOVA and Dunnett's test) (Figure 5a and b). The inhibitory effect of cocaine was less pronounced and shorter than the one induced by morphine. There was also no significant change in CV after the psychostimulant administration (basal CV: $30.9 \pm 4.6 \%$; cocaine CV: $34.3 \pm 6.2 \%$; $p>0.05$, Student's $t$-test).

As cocaine-induced plasticity at excitatory synapses in the VTA has a crucial function in those adaptations contributing and promoting addictive behaviors (Chen et al, 2010), we decided to examine whether it could trigger similar changes in the RMTg. Bath application of cocaine $(1 \mu \mathrm{M}, 5 \mathrm{~min})$ caused no change in all measured parameters: in fact, neither EPSC amplitude (108.0 $\pm 16.7 \%$ of baseline; $n=5$; $\mathrm{F}_{18,72}=0.80 ; p=0.68$; one-way ANOVA) (Figure $5 \mathrm{c}$ and $\mathrm{d}$ ) nor paired-pulse ratio (EPSC2/EPSC1 from $0.97 \pm 0.10$ to $1.03 \pm 0.10 ; n=5, t=0.5583 ; p=0.6$; paired $t$-test) were affected. In addition, no changes were detected in either mean value of the decay time constant (being $5.03 \pm 0.08$ and $4.87 \pm 0.05 \mathrm{~ms}$ in the absence and presence of cocaine, respectively) or the holding current (being the change of $-0.76 \pm 4.15 \mathrm{pA}$ ) or input resistance (from $0.39 \pm 0.05$ to $0.48 \pm 0.1 \mathrm{G} \Omega$ ). This lack of effect could be ascribed to the specificity of acute effect of cocaine on DA neurons, which appears to be merely on NMDA-mediated EPSCs (Schilstrom et al, 2006).

WIN55212-2. CB1 receptors are widely distributed in the central nervous system, being mostly located in presynaptic terminals (Freund et al, 2003) in which they modulate both inhibitory and excitatory neurotransmission in neuronal subpopulations relevant to responses to rewarding and aversive stimuli (reviewed in Moreira and Lutz, 2008). Moreover, as DA neurons are excited by cannabinoids (French et al, 1997; Gessa et al, 1998), we hypothesized that inhibition of RMTg neurons could contribute to this effect. Hence, we thought to examine the effect of acute exposure to the CB1 receptor agonist WIN on seven putative RMTg neurons, which were identified by their excitatory responses to both $\mathrm{LHb}$ stimulation and paw pinch. Similarly to morphine, WIN $(0.5 \mathrm{mg} / \mathrm{kg}$, i.v. $)$ produced a profound and long-lasting decrease in discharge frequency $(46.9 \pm 6.7 \%$ of baseline level; $n=7 ; \mathrm{F}_{5,30}=19.44 ; p<0.0001$; one-way ANOVA and Dunnett's test) (Figure 6a and c), whereas no considerable changes were observed in the regularity of firing (basal CV: $31.0 \pm 5.0 \%$; WIN CV: $38.5 \pm 3.6 \%$; $p>0.05$, Student's $t$-test).

To clarify the involvement of $\mathrm{CB} 1$ receptors in this effect, we administered the CB1 receptor antagonist SR141716A (SR, $0.5 \mathrm{mg} / \mathrm{kg}$, i.v.) $4 \mathrm{~min}$ before WIN (Figure $6 \mathrm{~b}$ and c). SR, while per se ineffective, fully prevented WIN-induced depression of putative RMTg neurons $(102.6 \pm 3.1 \%$ of baseline level; $n=4 ; \quad \mathrm{F}_{1,45}=16.08 ; p<0.01$; two-way ANOVA and Bonferroni's test) (Figure $6 \mathrm{~b}$ and $\mathrm{c}$ ).

As $\mathrm{CB} 1$ receptor activation by endogenous ligands has been shown to modulate synaptic transmission in many brain regions (Kano et al, 2009), we examined whether WIN would affect excitatory transmission onto putative RMTg cells. WIN ( $1 \mu \mathrm{M}, 5 \mathrm{~min})$ significantly and irreversibly reduced EPSC amplitude (by $30.0 \pm 4.0 \%$; $n=5$; $\mathrm{F}_{18,90}=3.62 ; p<0.0001$; one-way ANOVA) (Figure 6d). Probably because of its high lipophilicity, WIN effect did not wash out. However, when it was co-applied with the potent and selective CB1 receptor antagonist AM281 $(0.5 \mu \mathrm{M})$, WIN-induced inhibition of EPSC amplitude was fully prevented $\left(n=5 ; \quad \mathrm{F}_{1,171}=5.30 ; p<0.05\right.$; two-way ANOVA) (Figure 6e). WIN did not affect either the mean value of the decay time constant (being $4.66 \pm 0.2$ and $4.86 \pm 0.3 \mathrm{~ms}$ in the absence and presence of WIN, respectively) or the holding current (being the change of 

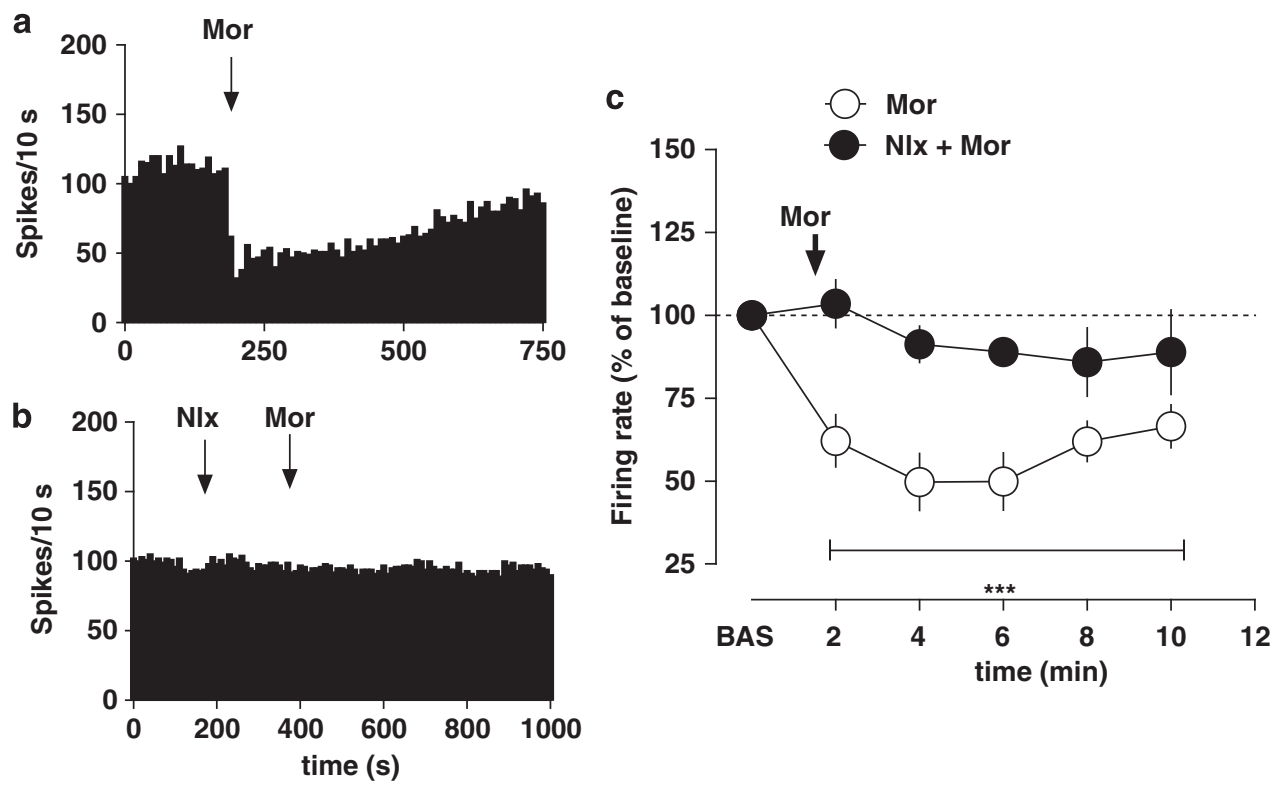

d

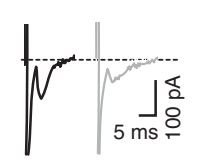

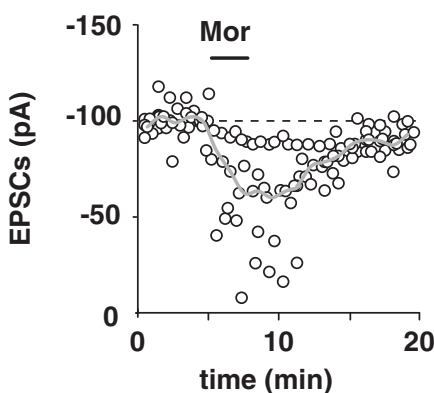

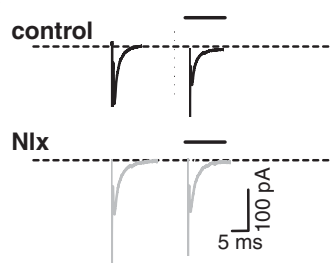

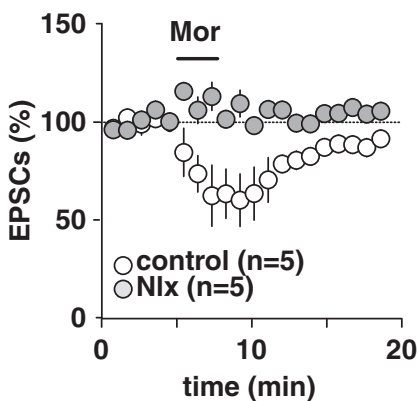

f
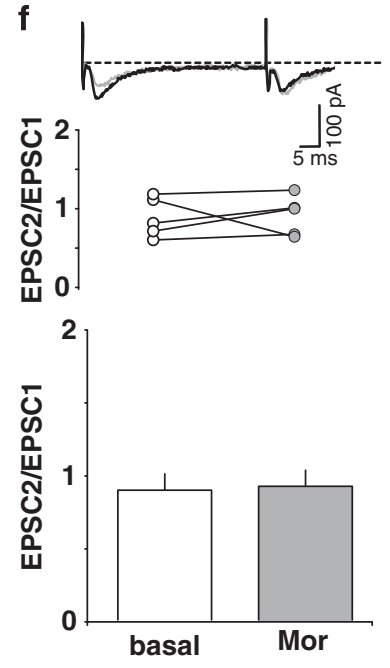

Figure 4 Effects of morphine on rostromedial tegmental nucleus (RMTg) neurons. (a) Representative firing rate histogram showing the inhibitory effects of i.v. morphine (Mor, $4 \mathrm{mg} / \mathrm{kg}$ injected at arrow) on discharge activity of an individual putative RMTg neuron. (b) Representative firing rate histogram showing that naloxone (Nlx, $0.1 \mathrm{mg} / \mathrm{kg}$, i.v. injected $4 \mathrm{~min}$ before morphine) fully prevents morphine-induced inhibition of firing rate of an RMTg neuron. (c) Graph illustrating the time course of morphine's effects ( $4 \mathrm{mg} / \mathrm{kg}$, i.v.) on firing rate of putative RMTg neurons with and without naloxone (0.I mg $/ \mathrm{kg}$, i.v.) pretreatment. Naloxone blocked the inhibition of RMTg neurons induced by morphine (arrow). The results are means with vertical bars representing the SEM of firing rate expressed as a percentage of the baseline (BAS). **** $p<0.00$ I vs baseline, one-way ANOVA and Dunnett's test. (d) Morphine induces inhibition of glutamatergic synaptic transmission in rat RMTg cells. A typical whole-cell patch-clamp recording showing that bath application of morphine $(\mathrm{I} \mu \mathrm{M})$ inhibits EPSC amplitude, when cells are held at $-70 \mathrm{mV}$. The gray line represents mean EPSC amplitude. The inset shows single EPSC from a typical experiment, before (black line) and during (gray line) superfusion of morphine. (e) Morphine reduces EPSC amplitude through activation of $\mu$-opioid receptors. All data are normalized to the respective baseline ( $5 \mathrm{~min}$ of baseline). Black bar shows time of superfusion of morphine in the presence (gray circles) and absence (open circles) of the $\mu$-opioid antagonist naloxone (I00 nM). SEM bars are smaller than symbols in some cases. The inset shows I2-trace averages of EPSCs in the absence (black line) and presence (gray line) of naloxone. Black bars represent time of morphine application. ( $f$ ) Morphine does not change the paired-pulse ratio of EPSCs. The top graph plots the paired-pulse ratio for each of the experiments in (e) before (open circles) and during (gray circles) the application of morphine, while the bottom graph plots the averaged paired-pulse ratio in a bar graph form. Representative traces are shown in the inset.

$4.67 \pm 2.60 \mathrm{pA}$ ) or the input resistance (from $0.49 \pm 0.05$ to $0.4 \pm 0.05 \mathrm{G} \Omega$ ). As probability of release is inversely related to paired-pulse ratio, if WIN decreases EPSC amplitude through activation of presynaptic CB1 receptors, one would expect an increased paired-pulse ratio in the presence of this drug. WIN-induced decrease of EPSC amplitude was accompanied by an increased paired-pulse ratio (EPSC2/
EPSC1 from $0.95 \pm 0.05$ to $1.45 \pm 0.20 ; n=5 ; t=3.039$; $p=0.019$; paired $t$-test) (Figure $6 \mathrm{f}$ ), thus suggesting that WIN reduced probability of glutamate release via activation of presynaptic CB1 receptors.

Nicotine. Acute injections of nicotine induce c-Fos expression specifically in non-DA neurons of the most caudal tier 

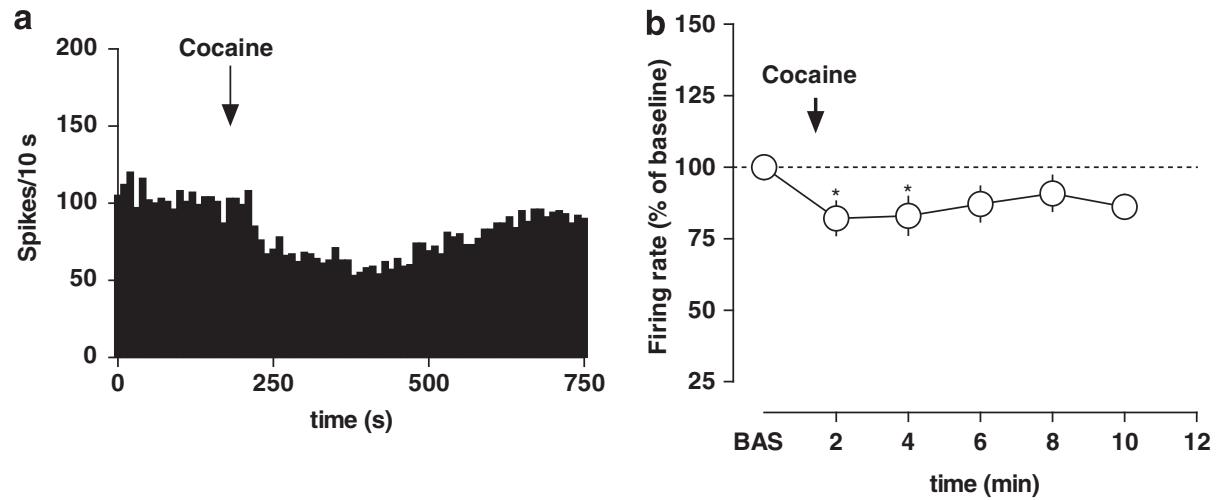
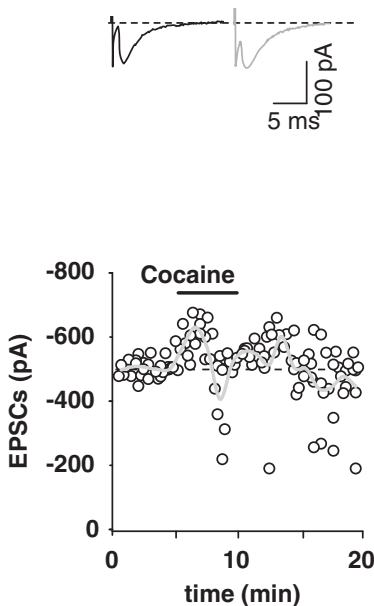

d
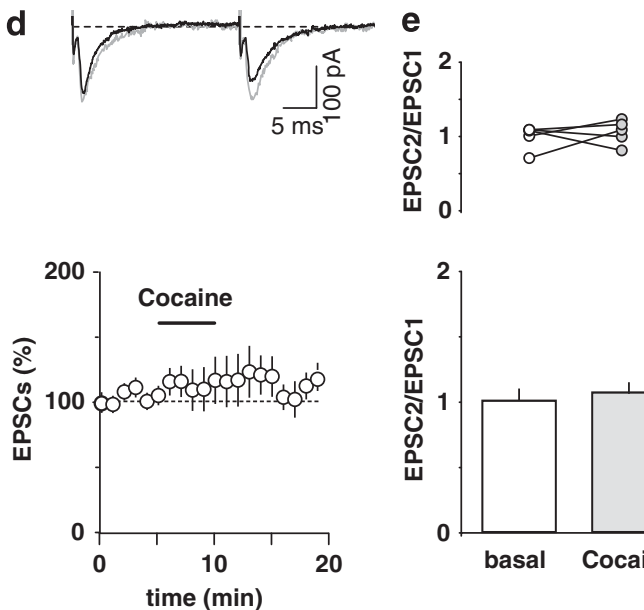

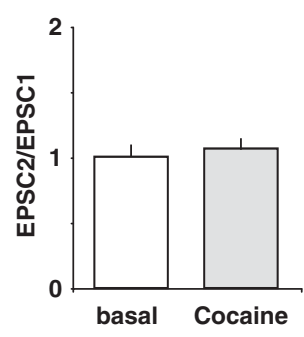

Figure 5 Cocaine's effects on rostromedial tegmental nucleus (RMTg) neurons. (a) Representative rate histogram illustrating the inhibition of firing rate of a putative RMTg neuron after cocaine administration (I mg/kg injected i.v. at arrow). (b) Graph showing the time course of cocaine's effects (I mg/kg, i.v.) on firing rate of putative RMTg neurons. The results are means with vertical bars representing the SEM of firing rate expressed as a percentage of baseline (BAS). ${ }^{*} p<0.05$ vs baseline, one-way ANOVA and Dunnett's test. (c) Cocaine does not affect glutamatergic synaptic transmission in rat putative RMTg cells. A typical whole-cell patch-clamp recording showing the effect of bath application of cocaine (I $\mu \mathrm{M})$ on EPSC amplitude, when cells are held at -70 mV. The gray line represents mean EPSC amplitude. The inset shows single EPSC from a typical experiment, before (black line) and during (gray line) application of cocaine. (d) Cocaine effect on EPSC amplitude. All data are normalized to the respective baseline ( 5 min of baseline). Black bar shows time of superfusion of cocaine. SEM bars are smaller than symbols in some cases. The inset shows 12 -trace averages of EPSCs in the absence (black line) and presence (gray line) of cocaine. Black bars represent time of cocaine application. (e) Cocaine does not change the paired-pulse ratio of EPSCs. The top graph plots the paired-pulse ratio for each of the experiments in (d) before (open circles) and during (gray circles) the application of cocaine, while the bottom graph plots the averaged paired-pulse ratio in a bar graph form. Representative traces are shown in the inset. Lines (black) represent EPSC amplitude before and during (gray line) application of cocaine.

of the rat VTA (Pang et al, 1993). Moreover, agonists at nicotinic acetylcholine receptors (nAChRs) have been reported to be more readily self-administered into the posterior than anterior VTA (Ikemoto et al, 2006). Thus, we next tested whether nicotine would affect the spontaneous activity of RMTg cells. We recorded seven putative RMTg neurons previously identified by both LHb stimulation and paw pinch. After 2-3 min of stable baseline activity, we administered nicotine $(0.2 \mathrm{mg} / \mathrm{kg}$, i.v.) (Figure $7 \mathrm{a}$ and $\mathrm{c}$ ). Nicotine caused a robust stimulation of firing rate $\left(198.8 \pm 29.2 \%\right.$ of baseline level; $n=7 ; \quad \mathrm{F}_{5,30}=6.63$; $p<0.001$; one-way ANOVA and Dunnett's test) (Figure 7c), without significantly affecting spiking regularity (basal CV: $34.1 \pm 3.8 \%$; nicotine CV: $33.0 \pm 3.8 \% ; p>0.05$, Student's $t$-test). We then asked if the nAChR antagonist mecamylamine ( $2 \mathrm{mg} / \mathrm{kg}$, i.v.) would antagonize nicotine's actions on putative RMTg cells. Administration of mecamylamine 4 min before nicotine did not alter spontaneous activity, but completely prevented nicotine-induced excitation $(100.7 \pm 10.7 \%$ of baseline level; $n=4 ; \mathrm{F}_{1,45}=18.98 ; p<0.01$; two-way ANOVA and Bonferroni's test) (Figure $7 \mathrm{~b}$ and $\mathrm{c}$ ), thus supporting the role of nAChRs in the observed effects.

In vitro, nicotine $(1 \mu \mathrm{M}, 2 \mathrm{~min})$ also produced a longlasting enhancement of EPSC amplitude (by $40.0 \pm 7.0 \%$ in the presence of nicotine; $n=5 ; \mathrm{F}_{18,72}=10.13 ; p<0.0001$; one-way ANOVA) (Figure 7d). This effect was accompanied by an increased mean value of decay time constant (from $4.5 \pm 0.1$ to $5.8 \pm 0.2 \mathrm{~ms} ; p=0.005$; paired $t$-test), which corresponds well with the increased EPSC amplitude. We also observed that the decay time constant of EPSCs showed a positive correlation with peak amplitude (Figure $7 \mathrm{~d}$ ). This correlation was presumably not filtered by properties of the cell membrane, as neither the holding current (being $44.2 \pm 13.2$ and $47.9 \pm 14.6 \mathrm{pA}$ for baseline and nicotine, respectively) nor the input resistance (from $0.34 \pm 0.1$ to $0.38 \pm 0.1 \mathrm{M} \Omega$ ) changed during nicotine application. The positive relationship between the decay time constant and the peak amplitude might suggest a dependency of 
a

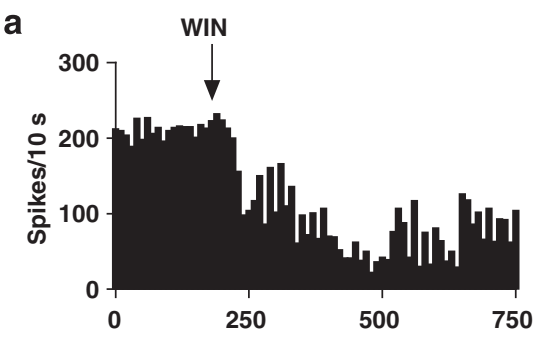

b

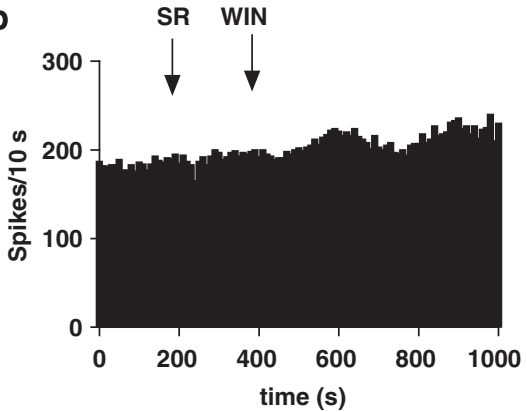

C
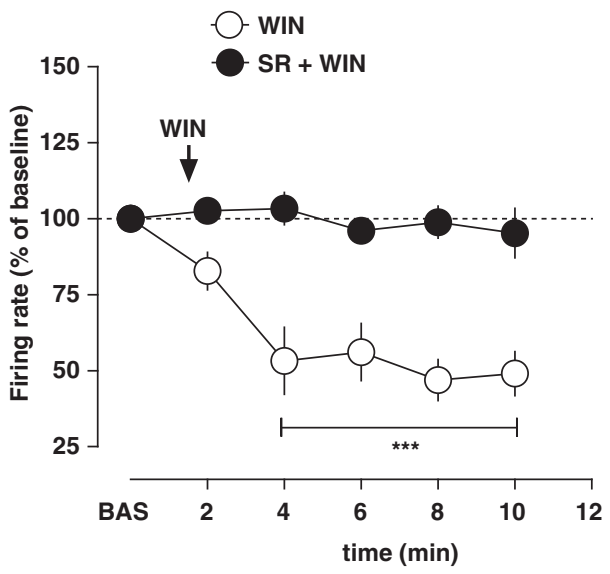

d

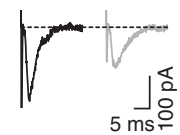

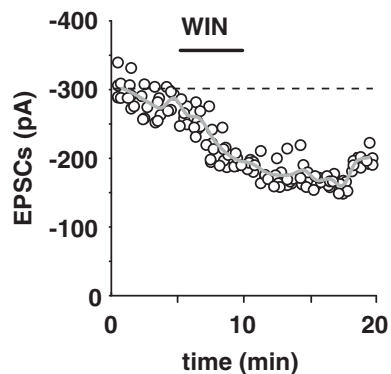

e
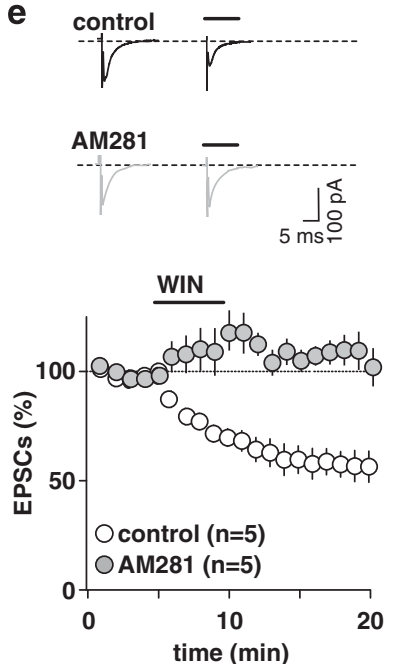

f
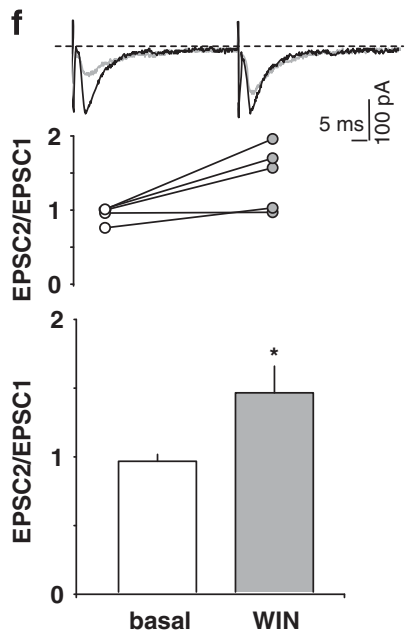

Figure 6 Responses of rostromedial tegmental nucleus (RMTg) neurons to the cannabinoid receptor agonist WIN552 I2-2 (WIN). (a) Typical firing rate histogram showing the inhibitory response of a putative RMTg neuron after WIN (0.5 mg/kg, i.v.) administration (arrow). (b) Representative rate histogram showing that the CBI antagonist SRI4I7I6A (SR, $0.5 \mathrm{mg} / \mathrm{kg}$, injected i.v. 4 min before WIN, at arrows) blocks WIN-induced inhibition of firing rate. (c) Graph showing the time course of WIN-induced inhibition of putative RMTg neurons, and that this inhibition by WIN was prevented by the administration (arrow) of SR $(0.5 \mathrm{mg} / \mathrm{kg}$, i.v.). The results are means with vertical bars representing the SEM of firing rate expressed as a percentage of baseline (BAS). **** $p<0.000$ I vs baseline, one-way ANOVA and Dunnett's test. (d) WIN inhibits glutamatergic synaptic transmission in rat putative RMTg cells. A typical whole-cell patch-clamp recording showing that bath application of WIN (I $\mu \mathrm{M})$ inhibits EPSC amplitude, when cells are held at -70 mV. The gray line represents mean EPSC amplitude. The inset shows single EPSC from a typical experiment, before (black line) and during (gray line) perfusion of WIN. (e) WIN reduces EPSC amplitude through activation of CBI receptors. All data are normalized to the respective baseline (5 min of baseline). Black bar shows time of superfusion of WIN in the presence (gray circles) and absence (open circles) of the CBI receptor antagonist AM28I (500 nM). SEM bars are smaller than symbols in some cases. The inset shows 12-trace averages of EPSCs in the absence (black line) and presence (gray line) of AM28I. Black bars represent time of WIN application. (f) WIN enhances the paired-pulse ratio of EPSCs, producing paired-pulse facilitation. The top graph plots the pairedpulse ratio for each of the experiments in (e) before (open circles) and during (gray circles) the application of WIN, while the bottom graph plots the averaged paired-pulse ratio in a bar graph form. Representative traces are shown in the inset, in which the EPSCs are represented before (black lines) and during WIN (gray lines) application. ${ }^{*} p<0.05$, Student's $t$-test.

amplitude on the rate of glutamate diffusion from the terminal to the synaptic cleft (Glavinovic and Rabie, 1998; Hirasawa et al, 2001). Notably, nicotine-induced potentiation of EPSC amplitude was sensitive to methyllycaconitine $(5 \mathrm{nM})$, an antagonist of $\alpha 7$-subtype nAChR subunit $(n=5$; $\mathrm{F}_{1,152}=17.87 ; p=0.0029$; two-way ANOVA) (Figure 7e). As nicotine-induced enhancement of EPSC amplitude is associated with a decrease in the paired-pulse ratio (EPSC2/ EPSC1 from $1.01 \pm 0.07$ to $0.82 \pm 0.05 ; n=5 ; t=2.45$; $p=0.03$; paired $t$-test) (Figure $7 \mathrm{f}$ ), altogether these data suggest that $\alpha 7$ subunits are the major components of nAChRs located on glutamatergic presynaptic terminals onto RMTg neurons, and might mediate the long-lasting excitation of putative RMTg neurons observed in vivo. 


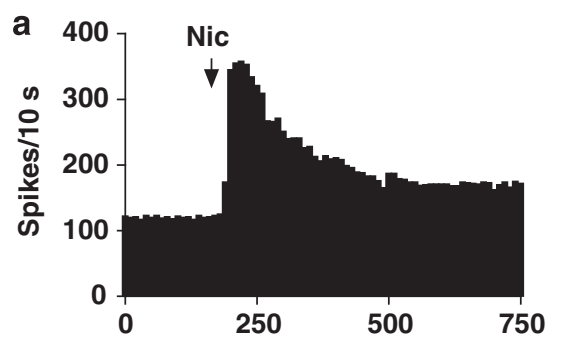

C
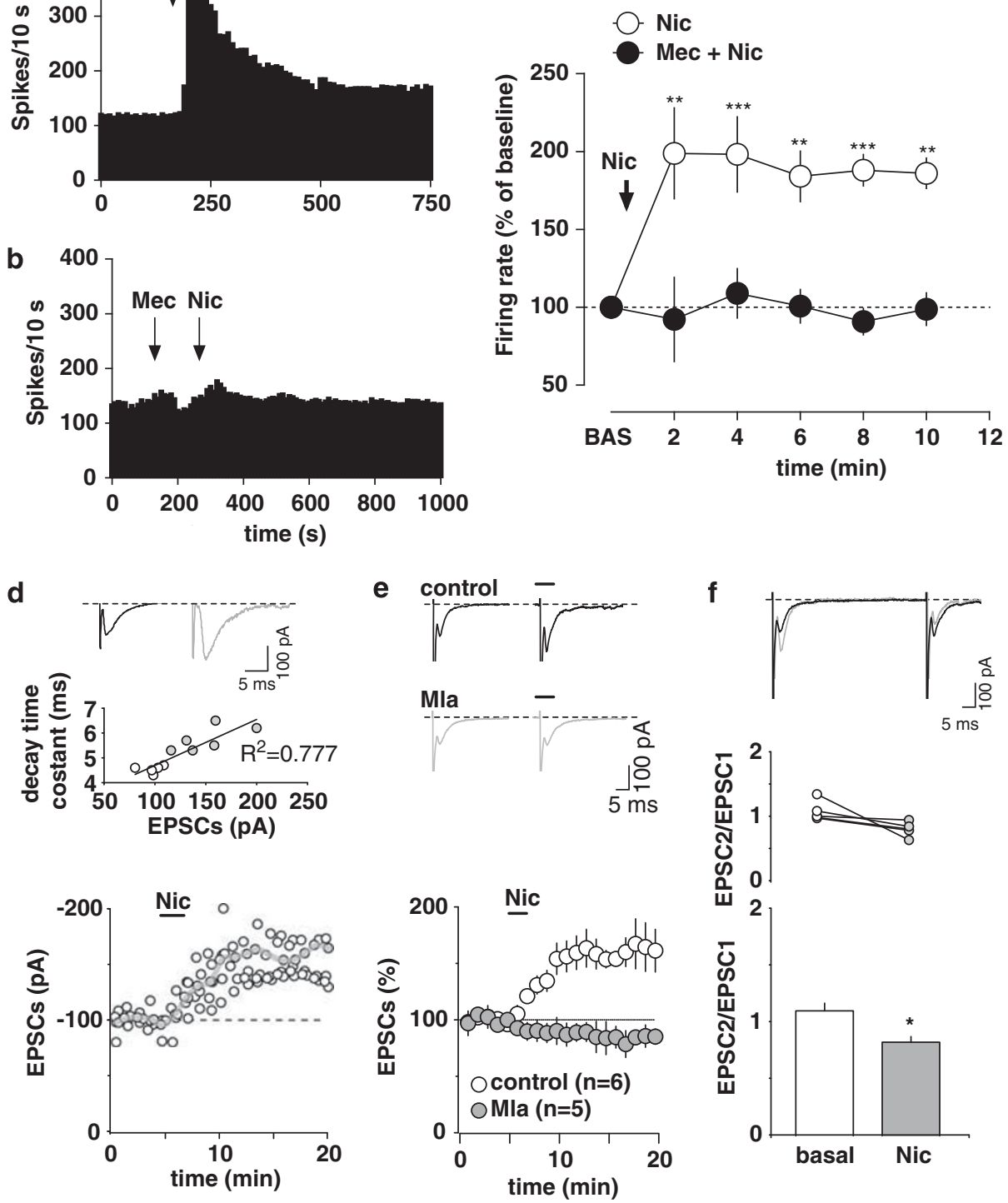

Figure 7 Rostromedial tegmental nucleus (RMTg) neurons are excited by nicotine. (a) Representative rate histogram showing that nicotine (Nic, $0.2 \mathrm{mg} / \mathrm{kg}$, i.v., arrow) strongly excites firing activity of a putative RMTg neuron. (b) This example shows that the non-selective nicotinic receptor antagonist mecamylamine ( $\mathrm{Mec}, 2 \mathrm{mg} / \mathrm{kg}$, i.v. $4 \mathrm{~min}$ before nicotine, arrow) fully prevents the effects of nicotine. (c) Graph showing the time course of the stimulation of firing rate induced by nicotine. Mecamylamine pretreatment fully prevents nicotine-induced stimulation of firing rate. The results are means with vertical bars representing the SEM of firing rate expressed as a percentage of the baseline (BAS). *** $<0.01$, **** $p<0.00$ I vs baseline, one-way ANOVA and Dunnett's test. (d) Nicotine enhances glutamatergic synaptic transmission in rat putative RMTg cells. A typical whole-cell patch-clamp recording showing that bath application of nicotine ( $1 \mu \mathrm{M}$; Nic) increases EPSC amplitude, when cells are held at $-70 \mathrm{mV}$. The gray line represents mean EPSC amplitude. The inset shows single EPSC from a typical experiment, before (black line) and during (gray line) perfusion of nicotine. The graph shows that the decay time constant of EPSCs is positively correlates with peak amplitude. (e) Nicotine enhances EPSC amplitude through activation of $\alpha 7$-containing nicotinic receptors. All data are normalized to the respective baseline ( 5 min of baseline). Black bar shows time of superfusion of nicotine in the presence (gray circles) and absence (open circles) of the $\alpha 7$-subunit receptor antagonist methyllycaconitine ( $5 \mathrm{nM}$; Mla). SEM bars are smaller than symbols in some cases. The inset shows 12-trace averages of EPSCs in the absence (black line) and presence (gray line) of Mla. Black bars represent time of nicotine application. (f) Nicotine reduces the paired-pulse ratio of EPSCs, producing paired-pulse depression. The top graph plots the paired-pulse ratio for each of the experiments in (e) before (open circles) and during (gray circles) the application of nicotine, while the bottom graph plots the averaged paired-pulse ratio in a bar graph form. Representative traces are shown in the inset, in which the EPSCs are represented before (black lines) and during nicotine (gray lines) application. * $p<0.05$, Student's $t$-test.

\section{DISCUSSION}

Here, we studied putative RMTg neurons that were excited by LHb stimulation and aversive stimuli (eg paw pinch). Conversely, we show that VTA DA neurons are inhibited by RMTg stimulation. On these bases, we hypothesized that these anatomical and functional aspects of RMTg neurons would be consistent with sensitivity to addicting drugs, which are known to interfere with reward and aversion mechanisms. Indeed, here we found that these cells, selected for their excitatory response to both LHb stimulation and a noxious stimulus, are inhibited by morphine, cocaine, and 
the cannabinoid agonist WIN. In addition, patch-clamp experiments show that EPSCs recorded from putative RMTg neurons and evoked by stimulation of rostral fibers were unchanged by cocaine, whereas inhibited by both WIN and morphine, with presynaptic and postsynaptic mechanisms, respectively. Notably, we also found that nicotine exerts opposite effects to those of morphine and WIN, as it strongly enhances firing rate of putative RMTg neurons and persistently increases the magnitude of EPSCs. Accordingly, converging anatomical, physiological, and behavioral studies show that the RMTg encodes aversive stimuli similarly to the LHb and opposite to the VTA. RMTg neurons are considered as an intermediate site between the LHb, which sends an extensive excitatory innervation, and VTA DA neurons, which in response are uniformly inhibited.

The depressant effect of morphine on putative RMTg neurons is consistent with the finding that this nucleus displays immunoreactivity against $\mu$-opioid receptors (Jhou et al, 2009b), and supports the hypothesis that opioids excite VTA DA neurons also by inhibiting RMTg neurons. Notably, RMTg cells exert a tonic inhibition on DA cells (Ikemoto, 2010). Consistently, rats will self-administer opioids into the RMTg, but not in the adjoining regions (Jhou et al, 2009c). Morphine also depressed EPSCs without changing the paired-pulse ratio, although decreasing the input resistance, thus suggesting that it does not affect the probability of glutamate release and that the site of action is at postsynaptic $\mu$-opioid receptors. However, the presence of cesium in the recording pipette argues against activation of G-protein-coupled inward rectifier $\mathrm{K}^{+}$channels as contributing factors to the decreased input resistance (Davila et al, 2003; Lesage et al, 1995).

Differently from $\mu$-opioid receptors, CB1 receptors in the CNS are mostly localized presynaptically on a large variety of axon terminals to suppress neurotransmitter release (Freund et al, 2003). It is not currently known whether CB1 receptors are localized within the RMTg. However, the LHb displays a relative abundance of CB1 mRNA, when compared with other thalamic nuclei (Matsuda et al, 1993), suggesting that CB1 receptors may be localized presynaptically at excitatory afferents in the RMTg to control glutamate release. Alternatively, CB1 receptors might also be located on axon terminals of output neurons of the peri-aqueductal gray, one of the major afferents to the RMTg (Jhou et al, 2009a). The observations that the CB1 agonist WIN depresses EPSC amplitude on putative RMTg neurons, induces a paired-pulse facilitation, and inhibits firing rate in vivo are consistent with a presynaptic locus of CB1 receptors, whose activation leads to a decreased probability of glutamate release. In addition, one can speculate that inhibition of RMTg neurons by WIN might be one of the mechanisms contributing to cannabinoidinduced excitation of DA neurons in vivo (French et al, 1997; Gessa et al, 1998).

Cocaine was shown to evoke $\triangle$ FosB expression on GABA neurons in the VTA tail (Perrotti et al, 2005), and this indicates that psychostimulants might affect DA neurons through the RMTg-VTA projection. Here, we confirmed the finding that methamphetamine induces Fos expression within RMTg. Prior studies show that psychostimulants activate RMTg Fos much more than in adjacent regions, but in our study, Fos levels detected in RMTg neurons do not appear to be strikingly higher than surrounding areas. It must be pointed out that, differently from procedures for methamphetamine-induced Fos activation described in previous papers, here rats were further prepared for electrophysiological recordings with anesthesia, surgery, electrode insertion, and dye ejection. Those additional procedures might have interfered with Fos expression by increasing aspecific expression within surrounding areas.

Cocaine was found to depress firing rate of putative RMTg neurons in vivo. The mechanism underlying this effect remains to be established. As cocaine does not affect the magnitude of EPSC, and neither changes the pairedpulse ratio nor the membrane properties of these cells, we can only hypothesize that effects in vivo result from indirect actions of cocaine on RMTg neurons, possibly through a long synaptic loop, which does not directly involve effects on excitatory afferents from the LHb.

Differently from the other drugs studied here, nicotine induces a robust and persistent excitation on putative RMTg neuron firing rate and increases both EPSC amplitude and the mean value of the decay time constant, while decreases the paired-pulse ratio. Taken together, our findings are indicative of the enhancement of glutamate release from excitatory afferents likely induced by $\alpha 7-$ containing nAChRs located on presynaptic terminals. Habenular afferents are likely to express $\alpha 7$-containing nAChRs, given that intense in situ hybridization for transcripts encoding these receptors was detected in the habenula (Seguela et al, 1993). We cannot exclude, however, that nicotine excites RMTg neurons also by acting at somatodendritic nAChRs. Hence, subcellular localization of nAChRs is relevant for the functional impact of their activation: nAChRs are expressed both on presynaptic terminals, in which they directly modulate GABA release independent of action potential firing (Fisher et al, 1998; Lu et al, 1999; Radcliffe et al, 1999), and on cell bodies, in which modulation of GABA release depends on discharge activity (Alkondon et al, 1997; Alkondon et al, 1999; Frazier et al, 1998). Extensive evidence indicates that nicotine stimulates discharge rate of VTA DA neurons (Mereu et al, 1987; Pidoplichko et al, 1997). In apparent contradiction with those findings, our results suggest that DA neurons might be inhibited by nicotine-induced excitation of RMTg neurons. However, a transient inhibition of DA neurons precedes long-lasting excitation in some instances (Erhardt et al, 2002) and the net overall excitatory effect of nicotine on VTA DA neurons is considered to result from the combination of fast sensitizing stimulation of GABA release and slowly sensitizing potentiation of glutamate release within the VTA, as elegantly shown by Mansvelder et al (2002). Thus, it is conceivable that stimulation of RMTg neurons by nicotine may contribute to the elevation of GABA levels in the VTA, which is ultimately overcome by a larger and long-lasting potentiation of glutamate release inducing DA neuron excitation (Mansvelder et al, 2002). Consistently, in the VTA, nAChR-induced modulation of GABA transmission was completely tetrodotoxin sensitive, implying that these receptors are expressed far away from terminals (Mansvelder et al, 2002).

The inhibition evoked by addicting drugs, with the exception of nicotine, on discharge activity and/or EPSCs on putative RMTg neurons is consistent with the notion that 
aversive stimuli encoded by the LHb, relayed to the RMTg and finally conveyed to the VTA, might be attenuated in their magnitude by concomitant administration of addicting drugs. Hence, RMTg lesions blunt inhibitory behavioral responses, such as freezing elicited by aversive stimuli and open arm avoidance in the elevated plus maze (Jhou et al, 2009a). Consistently, both opioids and cannabinoids reduce the magnitude of aversion-elicited inhibitory behavioral responses (Haney and Miczek, 1994; Moreira et al, 2009; Vivian and Miczek, 1998). On the other hand, opposite to morphine and cannabinoid agonists, nicotine enhances behavioral responses to aversive stimuli, as it enhances contextual fear as evaluated by measuring freezing, a natural fear response in rodent (Gould and Wehner, 1999). Data on the effects of cocaine are conflicting, possibly because it is difficult to separate the locomotoractivating effects of the drug: in one study, impaired freezing was associated with locomotor sensitization (Morrow et al, 1995), whereas in other studies, enhanced conditioned startle, possibly related to decreased freezing (Gordon and Rosen, 1999), or no effect on fear conditioning, were observed (Burke et al, 2006).

Our results show that putative RMTg neurons are a site of action of major addicting drugs. Being an important relay inhibitory region to the VTA, the RMTg is involved in the regulation of firing discharge of VTA DA neurons, and, therefore, might have an important function in the mechanisms and functional aspects of drugs of abuse.

\section{ACKNOWLEDGEMENTS}

We thank Stefano Carta and Angelo Casu for their skillful technical assistance and the Regione Autonoma della Sardegna, Assessorato alla Programmazione, for the support given to SL and AL through the program 'Bursaries for Young Researchers.'

\section{DISCLOSURE}

The authors declare that, except for income received from their primary employer, no financial support or compensation has been received from any individual or corporate entity over the past 3 years for research or professional service and there are no personal financial holdings that could be perceived as constituting a potential conflict of interest.

\section{REFERENCES}

Alkondon M, Pereira EF, Barbosa CT, Albuquerque EX (1997). Neuronal nicotinic acetylcholine receptor activation modulates gamma-aminobutyric acid release from CA1 neurons of rat hippocampal slices. J Pharmacol Exp Ther 283: 1396-1411.

Alkondon M, Pereira EF, Eisenberg HM, Albuquerque EX (1999). Choline and selective antagonists identify two subtypes of nicotinic acetylcholine receptors that modulate GABA release from CA1 interneurons in rat hippocampal slices. J Neurosci 19: 2693-2705.

Atherton JF, Bevan MD (2005). Ionic mechanisms underlying autonomous action potential generation in the somata and dendrites of GABAergic substantia nigra pars reticulata neurons in vitro. J Neurosci 25: 8272-8281.

Balcita-Pedicino J, Omelchenko N, Bell R, Sesack SR (2009). The rostromedial mesopontine tegmentum as a relay between the lateral habenula and dopamine neurons in the ventral tegmental area: ultrastructural evidence in the rat program no 815.7/B91. 2009 Neuroscience Meeting Planner. Society for Neuroscience: Chicago, IL.

Brinschwitz K, Dittgen A, Madai VI, Lommel R, Geisler S, Veh RW (2010). Glutamatergic axons from the lateral habenula mainly terminate on GABAergic neurons of the ventral midbrain. Neuroscience 168: 463-476.

Brischoux F, Chakraborty S, Brierley DI, Ungless MA (2009). Phasic excitation of dopamine neurons in ventral VTA by noxious stimuli. Proc Natl Acad Sci USA 106: 4894-4899.

Burke KA, Franz TM, Gugsa N, Schoenbaum G (2006). Prior cocaine exposure disrupts extinction of fear conditioning. Learn Mem 13: 416-421.

Cahusac PM, Morris R, Salt TE, Hill RG (1990). Sensory responses of caudal trigeminal neurons to thermal and mechanical stimuli and their behavioural correlates in the rat. Neuroscience 36: 543-551.

Chen BT, Hopf FW, Bonci A (2010). Synaptic plasticity in the mesolimbic system: therapeutic implications for substance abuse. Ann N Y Acad Sci 1187: 129-139.

Christoph GR, Leonzio RJ, Wilcox KS (1986). Stimulation of the lateral habenula inhibits dopamine-containing neurons in the substantia nigra and ventral tegmental area of the rat. J Neurosci 6: 613-619.

Colussi-Mas J, Geisler S, Zimmer L, Zahm DS, Berod A (2007). Activation of afferents to the ventral tegmental area in response to acute amphetamine: a double-labelling study. Eur J Neurosci 26: 1011-1025.

Davila V, Yan Z, Craciun LC, Logothetis D, Sulzer D (2003). D3 dopamine autoreceptors do not activate G-protein-gated inwardly rectifying potassium channel currents in substantia nigra dopamine neurons. J Neurosci 23: 5693-5697.

Erhardt S, Schwieler L, Engberg G (2002). Excitatory and inhibitory responses of dopamine neurons in the ventral tegmental area to nicotine. Synapse 43: 227-237.

Fisher JL, Pidoplichko VI, Dani JA (1998). Nicotine modifies the activity of ventral tegmental area dopaminergic neurons and hippocampal GABAergic neurons. J Physiol Paris 92: 209-213.

Frazier CJ, Rollins YD, Breese CR, Leonard S, Freedman R, Dunwiddie TV (1998). Acetylcholine activates an alpha-bungarotoxin-sensitive nicotinic current in rat hippocampal interneurons, but not pyramidal cells. J Neurosci 18: 1187-1195.

French ED, Dillon K, Wu X (1997). Cannabinoids excite dopamine neurons in the ventral tegmentum and substantia nigra. Neuroreport 8: 649-652.

Freund TF, Katona I, Piomelli D (2003). Role of endogenous cannabinoids in synaptic signaling. Physiol Rev 83: 1017-1066.

Geisler S, Marinelli M, Degarmo B, Becker ML, Freiman AJ, Beales $M$ et al (2008). Prominent activation of brainstem and pallidal afferents of the ventral tegmental area by cocaine. Neuropsychopharmacology 33: 2688-2700.

Gessa GL, Melis M, Muntoni AL, Diana M (1998). Cannabinoids activate mesolimbic dopamine neurons by an action on cannabinoid CB1 receptors. Eur J Pharmacol 341: 39-44.

Glavinovic MI, Rabie HR (1998). Monte Carlo simulation of spontaneous miniature excitatory postsynaptic currents in rat hippocampal synapse in the presence and absence of desensitization. Pflugers Arch 435: 193-202.

Gordon MK, Rosen JB (1999). Lasting effect of repeated cocaine administration on acoustic and fear-potentiated startle in rats. Psychopharmacology (Berl) 144: 1-7.

Gould TJ, Wehner JM (1999). Nicotine enhancement of contextual fear conditioning. Behav Brain Res 102: 31-39.

Grace AA, Bunney BS (1983). Intracellular and extracellular electrophysiology of nigral dopaminergic neurons - 1. Identification and characterization. Neuroscience 10: 301-315.

Grace AA, Bunney BS (1984). The control of firing pattern in nigral dopamine neurons: burst firing. J Neurosci 4: 2877-2890. 
Haney M, Miczek KA (1994). Ultrasounds emitted by female rats during agonistic interactions: effects of morphine and naltrexone. Psychopharmacology (Berl) 114: 441-448.

Hikosaka O, Sesack SR, Lecourtier L, Shepard PD (2008). Habenula: crossroad between the basal ganglia and the limbic system. J Neurosci 28: 11825-11829.

Hirasawa H, Shiells R, Yamada M (2001). Blocking AMPA receptor desensitization prolongs spontaneous EPSC decay times and depolarizes H1 horizontal cells in carp retinal slices. Neurosci Res 40: 217-225.

Hutchison MA, Riley AL (2008). Adolescent exposure to nicotine alters the aversive effects of cocaine in adult rats. Neurotoxicol Teratol 30: 404-411.

Ikemoto S (2010). Brain reward circuitry beyond the mesolimbic dopamine system: a neurobiological theory. Neurosci Biobehav Rev (in press, originally published online 10 February 2010, doi:10.1016/j.neubiorev.2010.02.001).

Ikemoto S, Qin M, Liu ZH (2006). Primary reinforcing effects of nicotine are triggered from multiple regions both inside and outside the ventral tegmental area. J Neurosci 26: 723-730.

Jhou TC, Fields HL, Baxter MG, Saper CB, Holland PC (2009a). The rostromedial tegmental nucleus (RMTg), a GABAergic afferent to midbrain dopamine neurons, encodes aversive stimuli and inhibits motor responses. Neuron 61: 786-800.

Jhou TC, Geisler S, Marinelli M, Degarmo BA, Zahm DS (2009b). The mesopontine rostromedial tegmental nucleus: a structure targeted by the lateral habenula that projects to the ventral tegmental area of Tsai and substantia nigra compacta. J Comp Neurol 513: 566-596.

Jhou TC, Xu S, Ikemoto S (2009c). Self-administration of a muopioid agonist into the rostromedial tegmental nucleus (RMTg), a GABAergic afferent to midbrain dopamine neurons and other arousal systems Program No 683.1/GG66. 2009 Neuroscience Meeting Planner. Society for Neuroscience: Chicago, IL.

Ji H, Shepard PD (2007). Lateral habenula stimulation inhibits rat midbrain dopamine neurons through a GABA(A) receptormediated mechanism. J Neurosci 27: 6923-6930.

Kano M, Ohno-Shosaku T, Hashimotodani Y, Uchigashima M, Watanabe M (2009). Endocannabinoid-mediated control of synaptic transmission. Physiol Rev 89: 309-380.

Kaufling J, Veinante P, Pawlowski SA, Freund-Mercier MJ, Barrot $M$ (2009). Afferents to the GABAergic tail of the ventral tegmental area in the rat. J Comp Neurol 513: 597-621.

Lesage F, Guillemare E, Fink M, Duprat F, Heurteaux C, Fosset M et al (1995). Molecular properties of neuronal G-proteinactivated inwardly rectifying $\mathrm{K}+$ channels. J Biol Chem 270: 28660-28667.

Lu Y, Marks MJ, Collins AC (1999). Desensitization of nicotinic agonist-induced $[3 \mathrm{H}]$ gamma-aminobutyric acid release from mouse brain synaptosomes is produced by subactivating concentrations of agonists. J Pharmacol Exp Ther 291: 1127-1134.

Mansvelder HD, Keath JR, McGehee DS (2002). Synaptic mechanisms underlie nicotine-induced excitability of brain reward areas. Neuron 33: 905-919.

Marinelli M, Rudick CN, Hu XT, White FJ (2006). Excitability of dopamine neurons: modulation and physiological consequences. CNS Neurol Disord Drug Targets 5: 79-97.

Matsuda LA, Bonner TI, Lolait SJ (1993). Localization of cannabinoid receptor mRNA in rat brain. J Comp Neurol 327: 535-550.

Matsumoto M, Hikosaka O (2007). Lateral habenula as a source of negative reward signals in dopamine neurons. Nature 447: 1111-1115.
Melis M, Camarini R, Ungless MA, Bonci A (2002). Long-lasting potentiation of GABAergic synapses in dopamine neurons after a single in vivo ethanol exposure. J Neurosci 22: 2074-2082.

Melis M, Pillolla G, Luchicchi A, Muntoni AL, Yasar S, Goldberg SR et al (2008). Endogenous fatty acid ethanolamides suppress nicotine-induced activation of mesolimbic dopamine neurons through nuclear receptors. J Neurosci 28: 13985-13994.

Mereu G, Yoon KW, Boi V, Gessa GL, Naes L, Westfall TC (1987). Preferential stimulation of ventral tegmental area dopaminergic neurons by nicotine. Eur J Pharmacol 141: 395-399.

Moreira FA, Aguiar DC, Campos AC, Lisboa SF, Terzian AL, Resstel LB et al (2009). Antiaversive effects of cannabinoids: is the periaqueductal gray involved? Neural Plast 2009: 625469.

Moreira FA, Lutz B (2008). The endocannabinoid system: emotion, learning and addiction. Addict Biol 13: 196-212.

Morrow BA, Taylor JR, Roth RH (1995). Prior exposure to cocaine diminishes behavioral and biochemical responses to aversive conditioning: reversal by glycine/N-methyl-D-aspartate antagonist co-treatment. Neuroscience 69: 233-240.

Nie Z, Schweitzer P, Roberts AJ, Madamba SG, Moore SD, Siggins GR (2004). Ethanol augments GABAergic transmission in the central amygdala via CRF1 receptors. Science 303: 1512-1514.

Omelchenko N, Bell R, Sesack SR (2009). Lateral habenula projections to dopamine and GABA neurons in the rat ventral tegmental area. Eur J Neurosci 30: 1239-1250.

Pang Y, Kiba H, Jayaraman A (1993). Acute nicotine injections induce c-fos mostly in non-dopaminergic neurons of the midbrain of the rat. Brain Res Mol Brain Res 20: 162-170.

Paxinos G, Watson C (2007). The Rat Brain in Stereotaxic Coordinates, 7th edn. Elsevier Academic Press: London.

Perrotti LI, Bolanos CA, Choi KH, Russo SJ, Edwards S, Ulery PG et al (2005). DeltaFosB accumulates in a GABAergic cell population in the posterior tail of the ventral tegmental area after psychostimulant treatment. Eur J Neurosci 21: 2817-2824.

Pidoplichko VI, DeBiasi M, Williams JT, Dani JA (1997). Nicotine activates and desensitizes midbrain dopamine neurons. Nature 390: 401-404.

Radcliffe KA, Fisher JL, Gray R, Dani JA (1999). Nicotinic modulation of glutamate and GABA synaptic transmission of hippocampal neurons. Ann N Y Acad Sci 868: 591-610.

Schilstrom B, Yaka R, Argilli E, Suvarna N, Schumann J, Chen BT et al (2006). Cocaine enhances NMDA receptor-mediated currents in ventral tegmental area cells via dopamine D5 receptor-dependent redistribution of NMDA receptors. J Neurosci 26: 8549-8558.

Schultz W (2007a). Behavioral dopamine signals. Trends Neurosci 30: $203-210$.

Schultz W (2007b). Multiple dopamine functions at different time courses. Annu Rev Neurosci 30: 259-288.

Seguela P, Wadiche J, Dineley-Miller K, Dani JA, Patrick JW (1993). Molecular cloning, functional properties, and distribution of rat brain alpha 7: a nicotinic cation channel highly permeable to calcium. J Neurosci 13: 596-604.

Simpson GR, Riley AL (2005). Morphine preexposure facilitates morphine place preference and attenuates morphine taste aversion. Pharmacol Biochem Behav 80: 471-479.

Ungless MA, Magill PJ, Bolam JP (2004). Uniform inhibition of dopamine neurons in the ventral tegmental area by aversive stimuli. Science 303: 2040-2042.

Vivian JA, Miczek KA (1998). Effects of mu and delta opioid agonists and antagonists on affective vocal and reflexive pain responses during social stress in rats. Psychopharmacology (Berl) 139: 364-375.

Wise RA, Yokel RA, DeWit H (1976). Both positive reinforcement and conditioned aversion from amphetamine and from apomorphine in rats. Science 191: 1273-1275. 